\title{
Glycoside hydrolase gene transcription by Alicyclobacillus acidocaldarius during growth on wheat arabinoxylan and monosaccharides: a proposed xylan hydrolysis mechanism
}

\author{
Brady D. Lee ${ }^{1,2,4^{*}} \mathbb{D}$, William A. Apel ${ }^{1}$, Peter P. Sheridan ${ }^{2}$ and Linda C. DeVeaux ${ }^{3}$
}

\begin{abstract}
Background: Metabolism of carbon bound in wheat arabinoxylan (WAX) polysaccharides by bacteria requires a number of glycoside hydrolases active toward different bonds between sugars and other molecules. Alicyclobacillus acidocaldarius is a Gram-positive thermoacidophilic bacterium capable of growth on a variety of mono-, di-, oligo-, and polysaccharides. Nineteen proposed glycoside hydrolases have been annotated in the A. acidocaldarius Type Strain ATCC27009/DSM 446 genome. Experiments were performed to understand the effect of monosaccharides on gene expression during growth on the polysaccharide, WAX.

Results: Molecular analysis using high-density oligonucleotide microarrays was performed on A. acidocaldarius strain ATCC27009 when growing on WAX. When a culture growing exponentially at the expense of arabinoxylan saccharides was challenged with glucose or xylose, most glycoside hydrolases were downregulated. Interestingly, regulation was more intense when xylose was added to the culture than when glucose was added, showing a clear departure from classical carbon catabolite repression demonstrated by many Gram-positive bacteria. In silico analyses of the regulated glycoside hydrolases, along with the results from the microarray analyses, yielded a potential mechanism for arabinoxylan metabolism by A. acidocaldarius. Glycoside hydrolases expressed by this strain may have broad substrate specificity, and initial hydrolysis is catalyzed by an extracellular xylanase, while subsequent steps are likely performed inside the growing cell.
\end{abstract}

Conclusions: Glycoside hydrolases, for the most part, appear to be found in clusters, throughout the A. acidocaldarius genome. Not all of the glycoside hydrolase genes found at loci within these clusters were regulated during the experiment, indicating that a specific subset of the 19 glycoside hydrolase genes found in A. acidocaldarius were used during metabolism of WAX. While specific functions of the glycoside hydrolases were not tested as part of the research discussed, many of the glycoside hydrolases found in the A. acidocaldarius Type Strain appear to have a broader substrate range than that represented by the glycoside hydrolase family in which the enzymes were categorized.

Keywords: Alicyclobacillus acidocaldarius, Wheat arabinoxylan, Glycoside hydrolase, Microarray

\footnotetext{
*Correspondence: Brady.Lee@pnnl.gov

${ }^{4}$ Present Address: Pacific Northwest National Laboratory, Energy and Environment Directorate, Richland, WA, USA

Full list of author information is available at the end of the article
} 


\section{Background}

Alicyclobacillus acidocaldarius is a Gram-positive, sporeforming, thermophilic acidophile that grows optimally in strictly aerobic conditions at $60{ }^{\circ} \mathrm{C}$ and at $\mathrm{pH}$ levels between 3 and 4 . This bacterium was isolated from a hot spring in Nymph Creek area of Yellowstone National Park [1]. Originally classified as Bacillus acidocaldarius, it was reclassified as $A$. acidocaldarius based on the prevalence of $\omega$-cyclic fatty acids in the cell wall and an abbreviated helix 6 of the 16S rRNA [2]. A. acidocaldarius has subsequently been isolated from diverse habitats, including water and soil from geothermal sites, submarine hot springs, and orchard soils, and also as a contaminant in heat-processed foods (e.g., fruit juices) [3-8]. A. acidocaldarius has demonstrated the ability to gain cellular carbon and energy from a wide variety of 5- and 6-carbon sugars, including $\mathrm{L}$-arabinose, ribose, $\mathrm{D}$-xylose, $\mathrm{D}$-galactose, D-fructose, D-mannose, rhamnose, mannitol, and tagatose; the disaccharides D-turanose, melibiose, cellobiose, lactose, maltose, sucrose, and trehalose, as well as the more complex polysaccharides: cellulose, hemicellulose (xylan), starch, and glycogen [9].

Lignocellulosic biomass is currently being studied as a feedstock for producing fuels and chemicals $[10,11]$. Chemically, lignocellulose is a heterogeneous, threedimensional matrix made of carbohydrate, primarily hemicellulose (20-30\%) and cellulose (40-50\%), and lignin. These components are intertwined, providing a structure that is highly resistant to microbial degradation. The hemicellulose fraction accounts for nearly one-third of the renewable carbon found on Earth [12, 13]. Hemicellulose is composed predominantly of xylan, which consists of a conserved backbone of 1,4-linked $\beta$-Dxylose residues, decorated with side groups composed of arabinose, glucuronic acid, 4-O-methyl-glucuronic acid, and sometimes galactose [14].

A thorough understanding of polysaccharide, monosaccharide, and mixed saccharide metabolism by $A$. acidocaldarius will help determine the utility of this bacterium for lignocellulose depolymerization. In part, this can be accomplished by understanding the effect of transcriptional regulation [i.e., carbon catabolite repression (CCR) as one example] on expression of genes encoding glycoside hydrolases, which represents the first step in metabolism of lignocellulose. Genome analysis of $\mathrm{A}$. acidocaldarius has revealed the presence of all components of Gram-positive CCR, as well as other regulators of genes encoding enzymes for monosaccharide and polysaccharide metabolism. The purpose of this study was to monitor gene transcription during growth on the polysaccharide, WAX, and to monitor the regulatory effects of monosaccharides on transcription of $A$. acidocaldarius genes related to xylan use (i.e., glycoside hydrolases).
Analyses were performed using batch chemostat studies and global transcriptome analysis using high-density oligonucleotide microarray studies. This research represents the first transcriptome analysis of $A$. acidocaldarius growing on plant polysaccharides, such as WAX.

\section{Results}

\section{Glycoside hydrolase inventory of $A$. acidocaldarius}

Alicyclobacillus acidocaldarius represents a source of thermostable glycoside hydrolases for application as industrial catalysts for the hydrolysis of the cellulose and hemicellulose components of lignocellulose. To date, 19 glycoside hydrolase genes have been identified in the $A$. acidocaldarius genome [15], and $\beta$-galactosidase, $\alpha$-amylase, cellulase, neopullulanase, exo-pectinase, mannanase, $\beta$-glycosidase, and endoglucanase enzymes have been expressed and characterized [6, 9, 16-33]. Enzymes required for efficient depolymerization of lignocellulose, and glycoside hydrolase activities found encoded in the genome of $A$. acidocaldarius or have been characterized by other research laboratories using recombinant $A$. acidocaldarius enzymes, are shown (Table 1). Analysis of the $A$. acidocaldarius genome shows 19 gene loci that are annotated as glycoside hydrolases (EC 3.2.1.-), supporting the observed broad substrate range of $A$. acidocaldarius related to oligo- and polysaccharides for this bacterium (Table 2). Only three of the loci (Aaci_0048,

\section{Table 1 Glycoside hydrolase genes required for complete depolymerization of the cellulose and hemicellulose fractions of lignocellulose and enzymes encoded by genes in the $A$. acidocaldarius genome}

\begin{tabular}{|c|c|}
\hline $\begin{array}{l}\text { Glycosyl hydrolase activity required } \\
\text { for lignocellulose depolymerization }\end{array}$ & $\begin{array}{l}\text { Presence in } A \text {. } \\
\text { acidocaldarius }\end{array}$ \\
\hline \multicolumn{2}{|l|}{ Cellulose } \\
\hline Endo- $\beta-1,4-$ glucanase (EC 3.2.1.4) & $x$ \\
\hline 1,4- $\beta$-glucan glucanohydrolase (EC 3.2.1.74) & \\
\hline 1,4- $\beta$-glucan cellobiohydrolase (EC 3.2.1.91) & \\
\hline$\beta$-Glucosidase (EC 3.2.1.21) & $x$ \\
\hline \multicolumn{2}{|l|}{ Hemicellulose } \\
\hline Endo- $\beta-1,4$-xylanase (EC 3.2.1.8) & $x$ \\
\hline Exo- $\beta$-1,4-xylosidase or $\beta$-xylosidase (EC 3.2.1.37) & $x$ \\
\hline a-L-arabinofuranosidase (EC 3.2.1.55) & $x$ \\
\hline \multicolumn{2}{|l|}{ Endo-a-1,5-arabinanase (EC 3.2.1.99) } \\
\hline a-Glucuronidase (EC 3.2.1.139) & $x$ \\
\hline \multicolumn{2}{|l|}{ 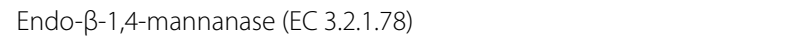 } \\
\hline \multicolumn{2}{|l|}{ 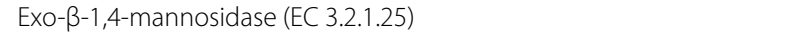 } \\
\hline \multicolumn{2}{|l|}{ a-Galactosidase (EC 3.2.1.22) } \\
\hline$\beta$-Glucosidase (EC 3.2.1.21) & $x$ \\
\hline \multicolumn{2}{|l|}{ Endo- $\beta$-1,4-galactanase (EC 3.2.1.89) } \\
\hline Acetylxylan esterase (EC 3.1.1.72) & $x$ \\
\hline \multicolumn{2}{|l|}{ Acetylmannan esterase (EC 3.1.1.6) } \\
\hline Ferulic and $p$-coumaric acid esterases (EC 3.1.1.73) & $x$ \\
\hline
\end{tabular}


Aaci_2457, and Aaci_2874) encode proteins that contain a signal peptide, which would indicate extracellular activity. The remaining enzymes are likely located and active in the periplasm or cytoplasm of $A$. acidocaldarius.

Extent of regulation of each of these genes during the experiment is presented, followed by an in-depth discussion of the bioinformatic analysis to assign function of the enzyme product from these genes. Microarray data discussed in this publication have been deposited in the National Center for Biotechnology Information (NCBI) Gene Expression Omnibus (GEO) and are accessible through GEO Series Accession Number GSE89078.

\section{Regulation of proposed arabinoxylan hydrolysis genes}

Gene transcription by $A$. acidocaldarius grown to midexponential phase on WAX was compared to transcription following the addition of glucose or xylose. Following initial exposure of the $A$. acidocaldarius growing on WAX to the monomer sugars, transcription of 13 of the 19 genes that encode putative glycoside hydrolases were downregulated, regardless of whether glucose or xylose was added (Fig. 1). In general, downregulation of glycoside hydrolase gene transcription was greater when xylose was added to the culture than

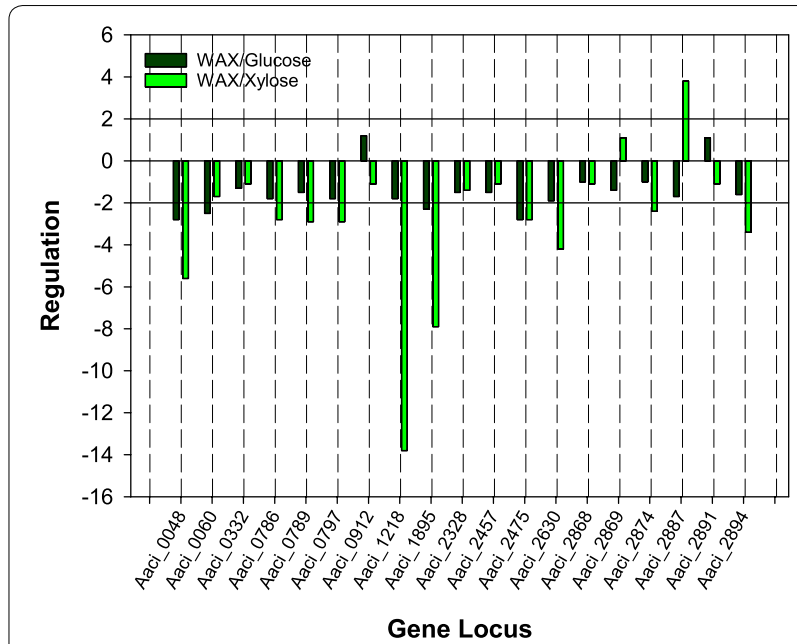

Fig. 1 Regulation of glycoside hydrolase genes in A. acidocaldarius when grown on WAX alone compared to regulation when growing on WAX and either glucose or xylose. See Table 2 for annotation of genes listed on $x$-axis

when glucose was added. This is puzzling because in most Gram-positive bacteria, the opposite has been shown [34, 35]. Two glycoside hydrolase genes were

Table 2 Identification of genome loci in A. acidocaldarius strain DSM 446 genome that encodes putative glycoside hydrolases

\begin{tabular}{|c|c|c|c|c|c|}
\hline Gene locus & Product name & $\begin{array}{l}\text { Enzyme Commission } \\
\text { number }\end{array}$ & Family & Signal sequence & $\begin{array}{l}\text { Transmembrane } \\
\text { helices }\end{array}$ \\
\hline Aaci_0048 & a-L-arabinofuranosidase-like protein & & & Yes $(24 / 25)$ & Yes \\
\hline Aaci_0060 & Xylan a-1,2-glucuronosidase & EC:3.2.1.131 & 67 & No & No \\
\hline Aaci_0332 & $\beta$-Glucosidase & EC:3.2.1.21 & 3 & No & No \\
\hline Aaci_0786 & a-Galactosidase & EC:3.2.1.22 & 36 & No & No \\
\hline Aaci_0789 & $\beta-1,4-m a n n a n a s e$ & $E C: 3.2 .1 .78$ & 113 & No & No \\
\hline Aaci_0797 & a-Galactosidase & $E C: 3.2 .1 .22$ & 4 & No & No \\
\hline Aaci_0912 & Amylo-a-1,6-glucosidase & EC:3.2.1.33 & 13 & No & No \\
\hline Aaci_1218 & $\beta$-Galactosidase & EC:3.2.1.23 & 2 & No & No \\
\hline Aaci_1895 & $\beta$-Galactosidase/ $\beta$-glucosidase & EC:3.2.1.21 & 1 & No & No \\
\hline Aaci_2328 & Endo-1,4- $\beta$-xylanase & EC:3.2.1.8 & 10 & No & No \\
\hline Aaci_2457 & Polygalacturonase & $E C: 3.2 .1 .15$ & 28 & Yes (33/34) & Yes \\
\hline Aaci_2475 & Endoglucanase C & EC:3.2.1.4 & 9 & No & No \\
\hline Aaci_2630 & $\beta$-Glucosidase/ $\beta$-xylosidase & $\begin{array}{l}E C: 3 \cdot 2 \cdot 1 \cdot 21 \\
E C: 3 \cdot 2 \cdot 1 \cdot 37\end{array}$ & 3 & No & No \\
\hline Aaci_2868 & a-Glucosidase & EC:3.2.1.20 & 31 & No & No \\
\hline Aaci_2869 & $\begin{array}{l}\text { Neopullulanase/cyclomaltodextrinase/ } \\
\text { maltogenic a-amylase }\end{array}$ & $\begin{array}{l}\text { EC:3.2.1.135 } \\
\text { EC:3.2.1.54 } \\
\text { EC:3.2.1.133 }\end{array}$ & 13 & No & No \\
\hline Aaci_2874 & a-Amylase & EC:3.2.1.1 & 13 & Yes $(23 / 24)$ & No \\
\hline Aaci_2887 & a-Xylosidase & EC:3.2.1.177 & 31 & No & No \\
\hline Aaci_2891 & $\beta$-Galactosidase & EC:3.2.1.23 & 42 & No & No \\
\hline Aaci_2894 & a-L-arabinofuranosidase & EC:3.2.1.55 & 51 & No & No \\
\hline
\end{tabular}

Classification of Enzyme Commission and glycoside hydrolase family numbers were obtained from the Carbohydrate-Active enZYme database (CAZY). Signal sequences and transmembrane helices were taken from JGI-IMG, and signal sequences were verified using the SignalP program 
upregulated when glucose was added (Aaci_0912 and Aaci_2891), while these same genes were downregulated when xylose was added. Aaci_0912, which is a proposed amylo- $\alpha-1,6$-glycosidase, was upregulated slightly over onefold (or a 2 times increase comparing final to initial gene transcription) when glucose was added. Since this locus was downregulated when xylose was added, the gene was being expressed at low levels when A. acidocaldarius was growing on WAX. Similarly, Aaci_2891, which encodes a $\beta$-galactosidase, was positively regulated when glucose was added, but downregulated when xylose was added. Again, regulation of Aaci_2891 was approximately onefold, regardless of sugar or direction of regulation. Two other glycoside hydrolase genes (Aaci_2869 and Aaci_2887) behaved in the opposite manner of the two genes just discussed and were upregulated when xylose was added but downregulated with glucose. One of these genes, Aaci_2887, which is proposed to encode a putative $\alpha$-xylosidase, was upregulated nearly fourfold with xylose, but was downregulated nearly twofold when glucose was added. The extent of downregulation (1.4-fold) of Aaci_2869 when glucose was added was greater than the magnitude of upregulation on xylose (onefold). Transcription of the remaining 15 glycoside hydrolase genes was downregulated following addition of either xylose or glucose. Gene locus Aaci_0048, which encodes a 959-amino acid protein annotated as a $\alpha-\mathrm{L}-$ arabinofuranosidase-like protein, was downregulated 5.6fold when xylose was added and 2.8-fold when glucose was added. Gene transcription from locus Aaci_0060 from $A$. acidocaldarius was downregulated 2.5 -fold when glucose was added and 1.7-fold when xylose was added. The putative protein product is annotated as an $\alpha-1,2$-glucuronidase, which is most likely involved in hydrolysis of 4-O-methyl-D-glucuronic acid or glucuronic acid, both of which are found as modifications of the xylan backbone of WAX. Transcription of gene loci Aaci_0786, Aaci_0789, and Aaci_0797 was downregulated during this experiment, and regulation was greater when xylose was supplied as the inducing sugar. These genes encode a putative $\alpha$-galactosidase, a hypothetical protein with a glycoside hydrolase catalytic domain, and a second $\alpha$-galactosidase, respectively. When xylose was added, transcription of gene locus Aaci_1218, a putative $\beta$-galactosidase, was downregulated nearly 14 -fold, but less than twofold when glucose was added. This gene locus was the most highly downregulated gene proposed to encode a glycoside hydrolase. A second gene (Aaci_1895) that has been annotated as a $\beta$-galactosidase/ $\beta$-glucosidase in glycoside hydrolase family 1 was downregulated 7.9-fold when xylose was added and 2.3-fold when glucose was added. A gene encoding a family 9 glycoside hydrolase (Aaci_2475) was downregulated equally
( 2.8-fold) when the exponentially growing $A$. acidocaldarius was exposed to xylose or glucose. The transcript for a 782-amino acid protein, encoded by genome locus Aaci_2630, was downregulated nearly twofold when glucose was added and greater than fourfold when xylose was added. This gene encodes a glycoside hydrolase family 3 domain protein with $\beta$-glucosidase or $\beta$-xylosidase activity. While transcription of genes encoding enzymes that would be active toward glucose polymers would not be expected during growth on a xylan substrate, gene loci Aaci_2874, which encodes a protein annotated as an $\alpha$-amylase, was downregulated nearly threefold when xylose was added to the exponentially growing culture, but not with glucose. A gene annotated to encode an $\alpha$-arabinofuranosidase (Aaci_2894) was downregulated 3.4-fold when xylose was added to the logarithmically growing $A$. acidocaldarius culture, but less than twofold when glucose was added. Gene Aaci_2887, annotated as a glycoside hydrolase family 31 enzyme, was upregulated 3.8-fold when xylose was added, but downregulated 1.7fold when glucose was added.

\section{Regulation of other accessory genes associated with arabinoxylan hydrolysis}

When considering arabinoxylan compounds, the xylose backbone and sugar moieties attached to this backbone can also have acetyl and ferulic acid groups chemically bound in the arabinoxylan structure. For optimal liberation of the sugars in arabinoxylan, a number of carbohydrate esterases (CE) or deacetylase enzymes are also required for removal of these groups. Putative $C E$ enzymes attributed to A. acidocaldarius strain DSM 446 as annotated in the CAZy database are listed in Table 3. Typically, CE activity is attributed to families $1-7$ and 16 , acting on fragments generated by the activity of endo- $\beta$ 1,4-xylanases [36]. Proteins found in CE family 14, such as LmbE family proteins, have broad substrate specificity and can act as CE [37, 38]. Deacetylation activity by this group of enzymes is primarily associated with cell wall rearrangement and sporulation in bacteria, but the broad substrate specificity may allow these enzymes to act on acetyl moieties found in arabinoxylan or even chitin [39]. Six of the eight esterase-encoding genes were regulated during the experiments (Fig. 2).

Two (Aaci_1372 and Aaci_1443) of the four genes encoding CE family 4 enzymes were upregulated during the experiments. Aaci_1372 was upregulated to a greater extent when xylose was added to the $A$. acidocaldarius strain DSM 446 culture growing on WAX, while the converse was true for Aaci_1443, where greater upregulation was seen when glucose was added. The protein encoded by Aaci_1372 also contains a signal peptide indicating extracellular localization of this enzyme. The protein 
Table 3 Identification of genome loci in A. acidocaldarius strain DSM 446 genome that encodes putative carbohydrate deacetylase enzymes

\begin{tabular}{llllll}
\hline Gene locus & Product name & $\begin{array}{l}\text { Enzyme Commission } \\
\text { number }\end{array}$ & Family & $\begin{array}{l}\text { Signal } \\
\text { sequence }\end{array}$ & $\begin{array}{l}\text { Transmembrane } \\
\text { helices }\end{array}$ \\
\hline Aaci_0255 & Polysaccharide deacetylase & EC:3.1.1.72 3.5.1.- & 4 & No & No \\
Aaci_0863 & N-acetylglucosamine-6-phosphate deacetylase & EC:3.5.1.25 3.5.1.80 & 9 & No & No \\
Aaci_0881 & LmbE family protein & EC:3.5.1.- & 14 & No & No \\
Aaci_0954 & LmbE family protein & EC:3.5.1.- & 14 & No & No \\
Aaci_1372 & Polysaccharide deacetylase & EC:3.1.1.72 3.5.1.- & 4 & Yes (28/29) No & No \\
Aaci_1443 & Polysaccharide deacetylase & EC:3.1.1.72 3.5.1.- & 4 & No & No \\
Aaci_1912 & Polysaccharide deacetylase & EC:3.1.1.72 3.5.1.- & 4 & No & No \\
Aaci_2070 & LmbE family protein & EC:3.5.1.- & 14 & No & No
\end{tabular}

Classification of Enzyme Commission and carbohydrate deacetylase family numbers were obtained from the Carbohydrate-Active enZYme database (CAZY). Signal sequences and transmembrane helices were taken from JGI-IMG, and signal sequences were verified using the SignalP program

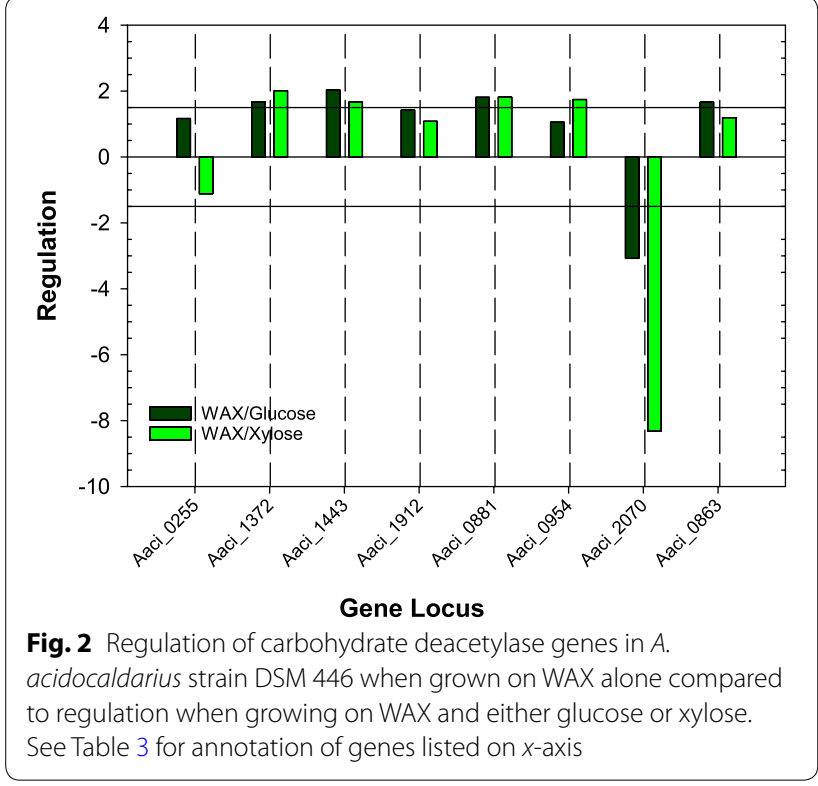

encoded by Aaci_1372 is homologous to putative xylanase and chitin deacetylase enzymes found in Desulfosporosinus species and to polysaccharide deacetylase enzymes in other Alicyclobacilli (Fig. 3). The putative CE family 4 esterase encoded by Aaci_1443 is homologous to polysaccharide deacetylases in other Alicyclobacilli, as well as xylanase/chitin deacetylase enzymes found in a variety of Anoxybacillus species. While substrate specificity of the proteins encoded by these two loci has not been determined, upregulation during the experiment and homology to other CE family 4 proteins may indicate that these enzymes are involved in deacetylation of arabinoxylan. One possibility is that these genes were expressed to remove the acetyl groups from small oligosaccharides, allowing further metabolism of the arabinoxylan fractions.
All three genes encoding LmbE family proteins found in the $A$. acidocaldarius strain DSM 446 genome were regulated during the experiments (see Table 3). Aaci_0881 was upregulated to similar levels when either glucose or xylose was added, while Aaci_0954 was only upregulated when xylose was added. In contrast, Aaci_2070 was downregulated during the experiments, 8.3-fold when xylose was added and threefold when glucose was added. Aaci_0881 and Aaci_0954 show homology to annotated deacetylases in other Alicyclobacilli and a number of Geobacillus species (Fig. 4). Aaci_2070 shows homology to deacetylases found in many hyperthermophiles. While this group of enzymes has been annotated as deacetylases, their specific function in arabinoxylan depolymerization, if any, is not known.

\section{Discussion}

Lignocellulose has three components-a hexosecontaining component (cellulose), a primarily pentose-containing component (hemicellulose), and an aromatic-containing component (lignin)-and accounts for a vast amount of carbon in the Earth's surface environment $[14,40]$. Due to the massive amount of this material in the environment, many microorganisms have developed the ability to hydrolyze the various components into oligomer and monomer units that are further metabolized for cellular processes, or fermented to produce alcohols and organic acids [41]. An important first step in metabolism of lignocellulose is the production of glycoside hydrolases that hydrolyze chemical linkages between the sugars, establishing the secondary structure of the polymeric compounds (i.e., cellulose, hemicellulose, and lignin). The primary objective of the current study was to understand gene transcription during growth on xylan (i.e., hemicellulose) by the Gram-positive thermoacidophile, A. acidocaldarius. To 


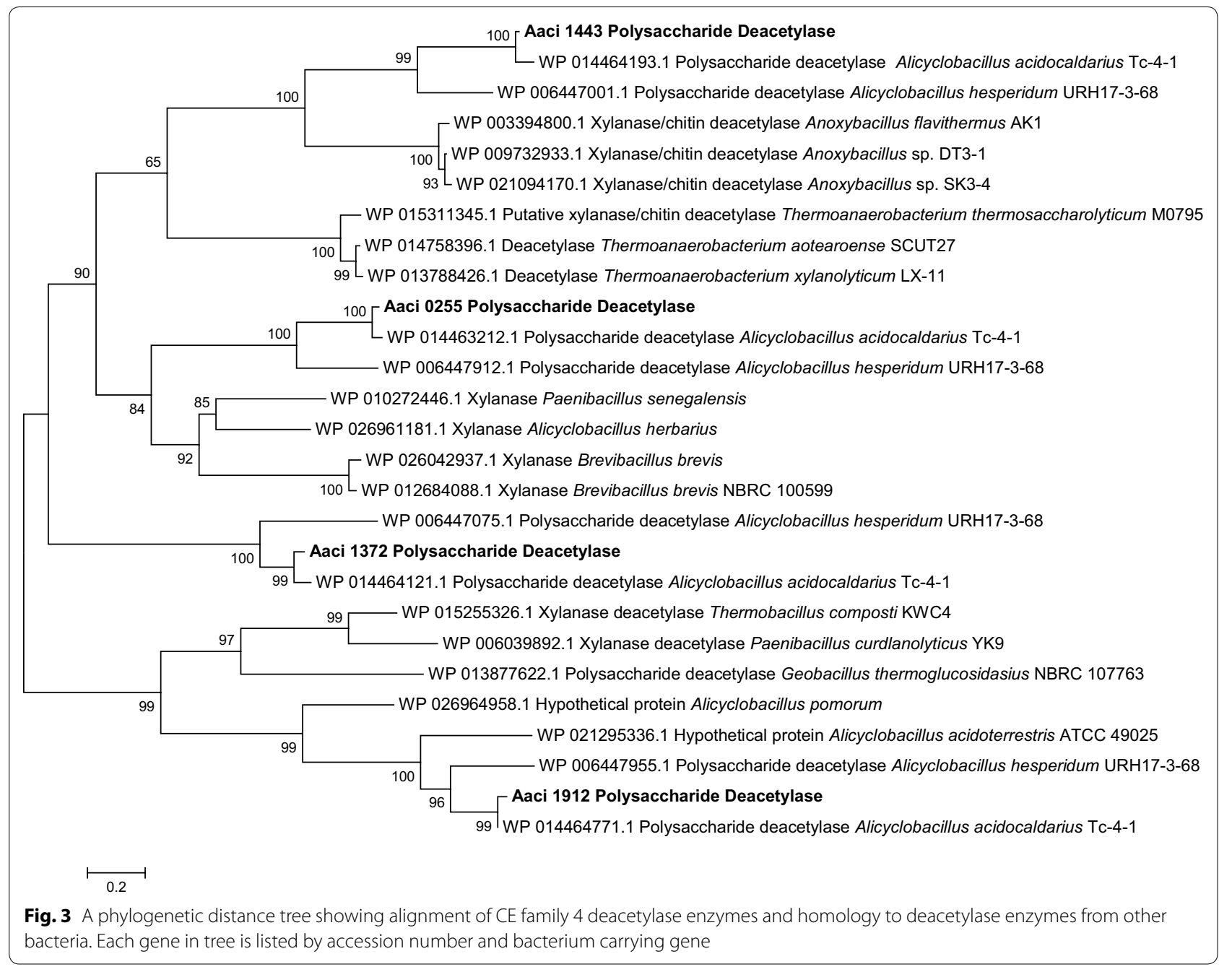

accomplish this objective, a physiological, molecular, and in silico approach was carried out to identify the specific glycoside hydrolases active when $A$. acidocaldarius is grown on hemicellulose provided in the form of WAX.

Molecular analysis was carried out using high-density oligonucleotide microarray studies, comparing gene expression of $A$. acidocaldarius during logarithmic growth on WAX, to gene expression after a monosaccharide, glucose, or xylose, was spiked into the growth medium. If genes were downregulated when the inducing sugar was added, the assumption was made that the protein product of the gene was being expressed during growth on WAX. Conversely, if genes were upregulated when the monosaccharide was added, the assumption was that the gene product was induced by the sugar. In silico analysis of the glycoside hydrolases expressed by $A$. acidocaldarius was used to determine how xylan metabolism in $A$. acidocaldarius is related to hemicellulose metabolism in other Bacteria and Archaea. Finally, the whole information was combined to propose a model for xylan metabolism by A. acidocaldarius (Fig. 5).

Steps in arabinoxylan metabolism hypothesized in this model include an initial extracellular depolymerization, followed by numerous steps inside the cell. The first step in the process is extracellular hydrolysis of $\beta$-1,4-bonds between internal xylopyranose residues in the arabinoxylan xylose backbone by the $\alpha$-arabinofuranosides-like enzyme encoded by Aaci_0048. Studies by Eckert and Schneider have shown xylanase activity by this enzyme [9]. Since the remaining enzymes that were downregulated during the experiment do not contain signal sequences, these enzymes are most likely active in the cytoplasm. Inside the cell, smaller $\beta$-D-xylopyranose oligosaccharides, including $\beta$-D-xylobiose, would be depolymerized by an endo-acting xylosidase (Aaci_0789 and Aaci_2328) and Aaci_2630 and Aaci_2887 for xylobiose molecules. The upregulation of Aaci_2887 indicates a shift in metabolism to hydrolyze xylobiose residues 


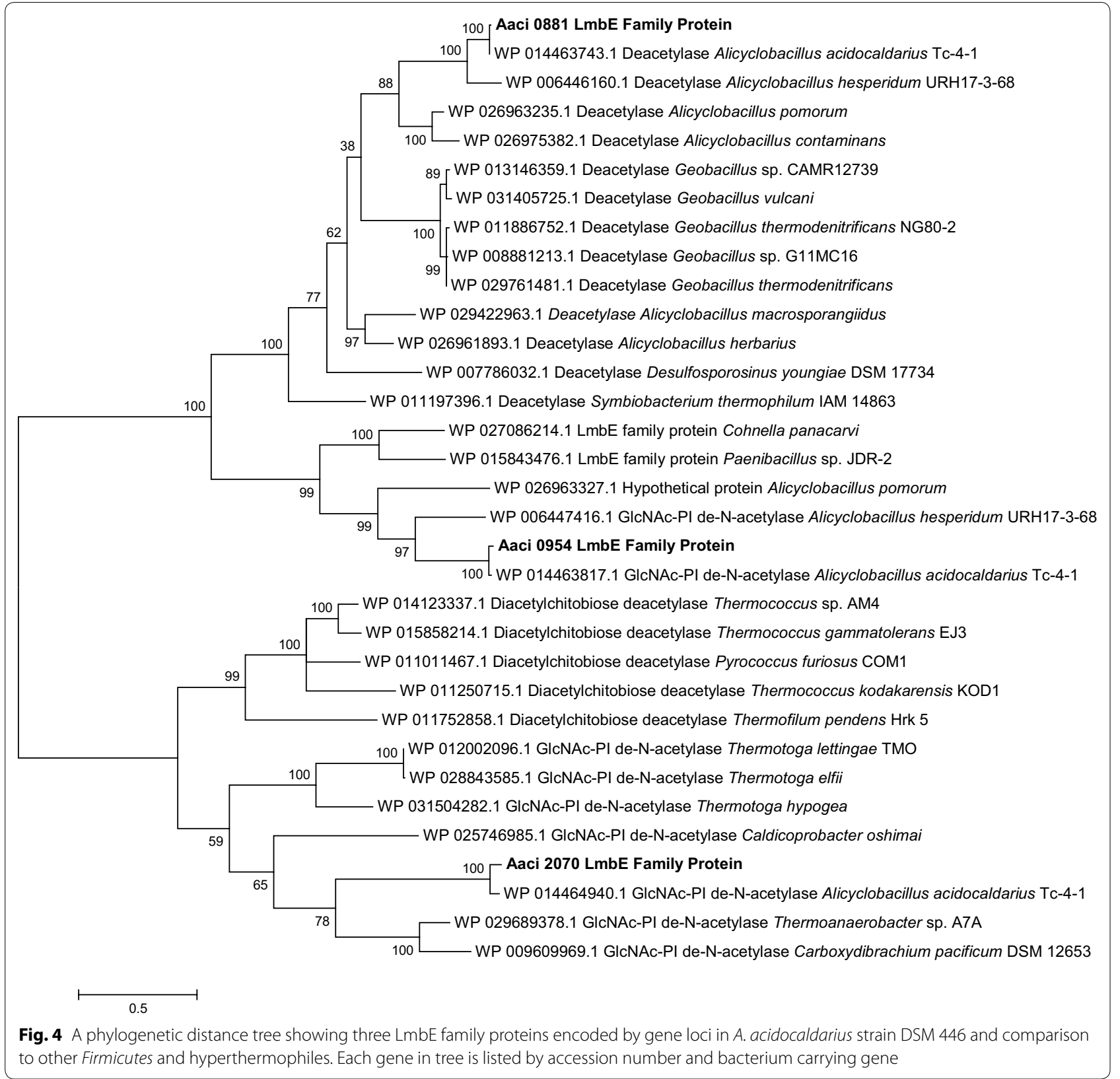

already inside the cell when the second sugar was added. Removal of $\alpha$-L-arabinofuranose side groups would then be catalyzed by the $\alpha$-L-arabinofuranosidase encoded by Aaci_2894. Approximately six enzymes that are annotated for putative activity toward 4-O-methyl glucuronic acid or galactose side groups were regulated during the experiments. While galactose is not shown in the schematic (Fig. 5), galactose is often found in arabinoxylan molecules [42]. Finally, a number of proposed esterase enzymes are thought to be active on acetyl- and feruloyl(not shown in model) groups on the xylan backbone.
Polysaccharide deacetylase (Aaci_1372 and Aaci_1443) and LmbE-like proteins (Aaci_0881, Aaci_0952, and Aaci_2070) were regulated during the experiment. Phylogenetic analysis of enzymes encoded by these genes indicated homology to other xylanase type enzymes (Fig. 2) and polysaccharide deacetylase (Fig. 3), which would be involved in removing acetyl side groups from the arabinoxylan molecule.

Bioinformatic analysis comparing the regulated $A$. acidocaldarius glycoside hydrolase genes to other bacteria allowed for putative verification of function for 


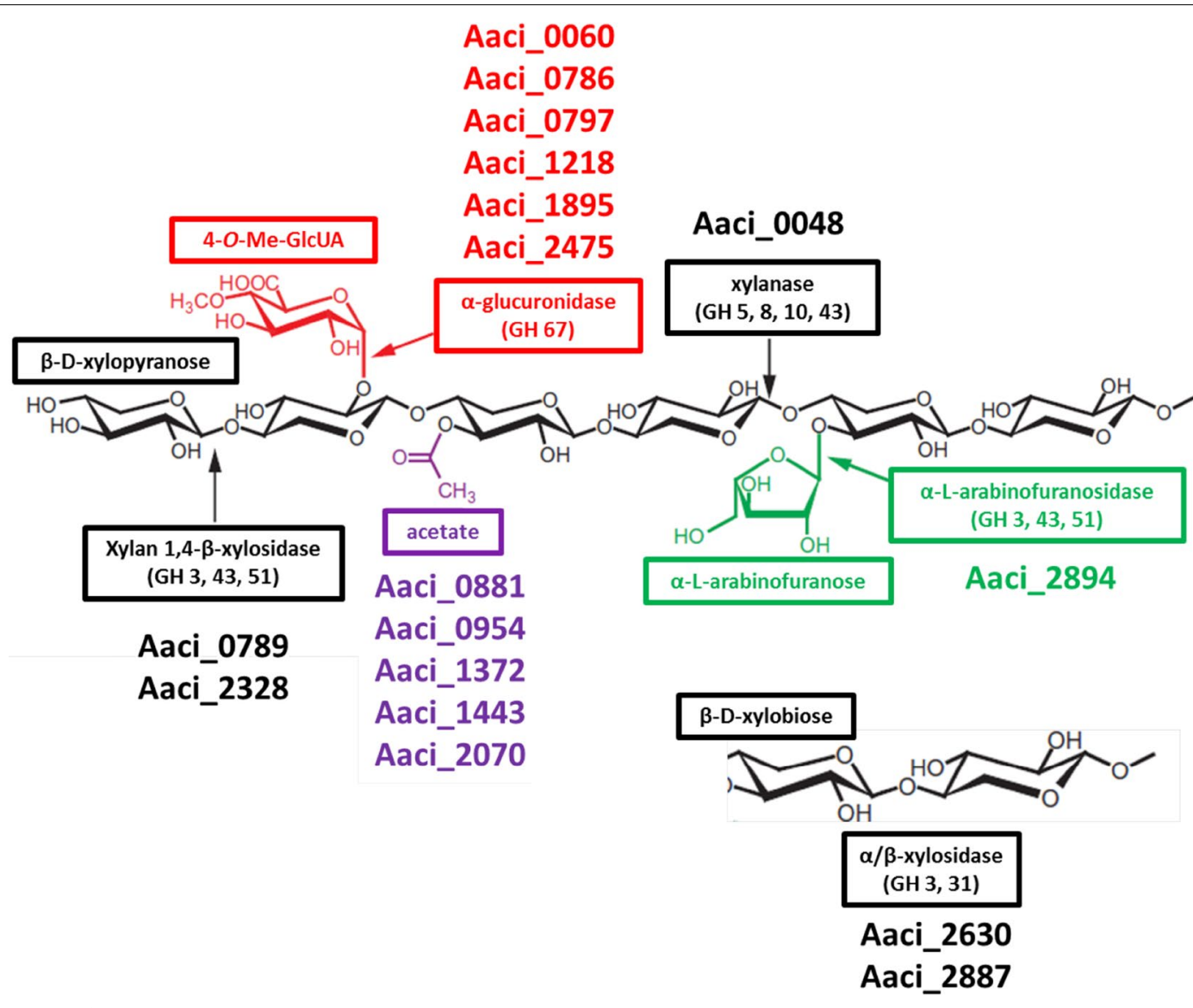

Fig. 5 Schematic of arabinoxylan showing chemical structure and proposed A. acidocaldarius strain DSM 446 genes annotated to produce enzymes catalyzing hydrolysis of specific bonds in the xylan backbone as well as functional groups attached to the backbone. See Tables 2 and 3 for description of gene products. GH family numbers listed are known to demonstrate common genes associated with hydrolysis of representative bonds, but they do not take into account increased specificity of other enzymes that may hydrolyze these bonds also

these genes in $A$. acidocaldarius. Comparison of gene locus Aaci_0048, which encodes a 959-amino acid protein annotated as a $\alpha$-L-arabinofuranosidase-like protein, shows conserved domains from the amino acid sequence are homologous to family 44 glycoside hydrolases, which indicate possible activity toward cellulose and xylan (i.e., endoglucanase activity). The $\mathrm{N}$-terminal domain of the protein also contains a sequence with close homology to carbohydrate binding domains of numerous glycoside hydrolases. Prior to publication of the A. acidocaldarius genome, Eckert and Schneider [9] expressed and characterized a 959-amino acid thermophilic endoglucanase (CelB; Accession AJ551527.1) from A. acidocaldarius with $100 \%$ identity to the gene product from Aaci_0048. The recombinant CelB enzyme demonstrated endoacting activity toward carboxy methyl cellulose, steamexploded cellulose and oat spelt xylan, demonstrating a broad substrate range for the enzyme. Sequencing and characterization of the enzyme classified it as an extracellular endoglucanase, with high sequence similarity to $\mathrm{GH}$ family 51 of arabinofuranosidases. While this enzyme has been annotated as a $\alpha$ - $\mathrm{L}$-arabinofuranosidase-like protein, no activity was demonstrated using $p$-nitrophenyl$\alpha$-L-arabinofuranoside. These results have been verified in unrelated studies at the Idaho National Laboratory for the native enzyme from $A$. acidocaldarius and a recombinant enzyme expressed from Pichia pastoris (data not shown). In total, these data indicate that the gene product from Aaci_0048 is a glycoside hydrolase protein that catalyzes hydrolysis of $\beta$-1,4-linked xylose subunits in the WAX xylan backbone. It should be noted that the glycoside hydrolase encoded by Aaci_0048 shares 43\% homology with a $\beta$-1,4-glucanase expressed from Alicyclobacillus sp. A4 [43].

The Homology Toolkit of the Integrated Microbial Genomes (IMG) Tool at JGI was used to compare the $\alpha$-L-arabinofuranosidase-like protein (Aaci_0048) from $A$. acidocaldarius to other genes within IMG. As would be expected, the protein showed the highest percent identity to similarly annotated genes in 
other species of Alicyclobacillus. The most closely related protein sequence from non-Alicyclobacillus was a cellulose binding family II protein from Ktedonobacter racemifer SOSP1-21. A distance tree generated from sequence information shows that, based on percent identity, Aaci_0048 had the highest homology to $\alpha$-arabinofuranosidases or cellulose binding family II proteins from numerous species of bacteria from the Order Actinomycetales (Fig. 6). Differences in activity between this enzyme and other $\alpha$-arabinofuranosidases in the database may be due to the additional 200-400 amino acids found in Aaci_0048 and the other similar proteins found in other strains of $A$. acidocaldarius. For comparison, the $\beta$-1,4-glucanase expressed from Alicyclobacillus sp. A4 still has fewer amino acids than the product of Aaci_0048, which contains an additional $\sim 250$ amino acids at the $\mathrm{C}$-terminus of the protein sequence. There is very little homology between Aaci_0048 and another annotated $\alpha$-arabinofuranosidase encoded by Aaci_2894 (discussed below). Evolutionarily, while the exact mechanism of catalysis is not known, an $\alpha$-arabinofuranosidase could have been transferred from an Actinomycete,

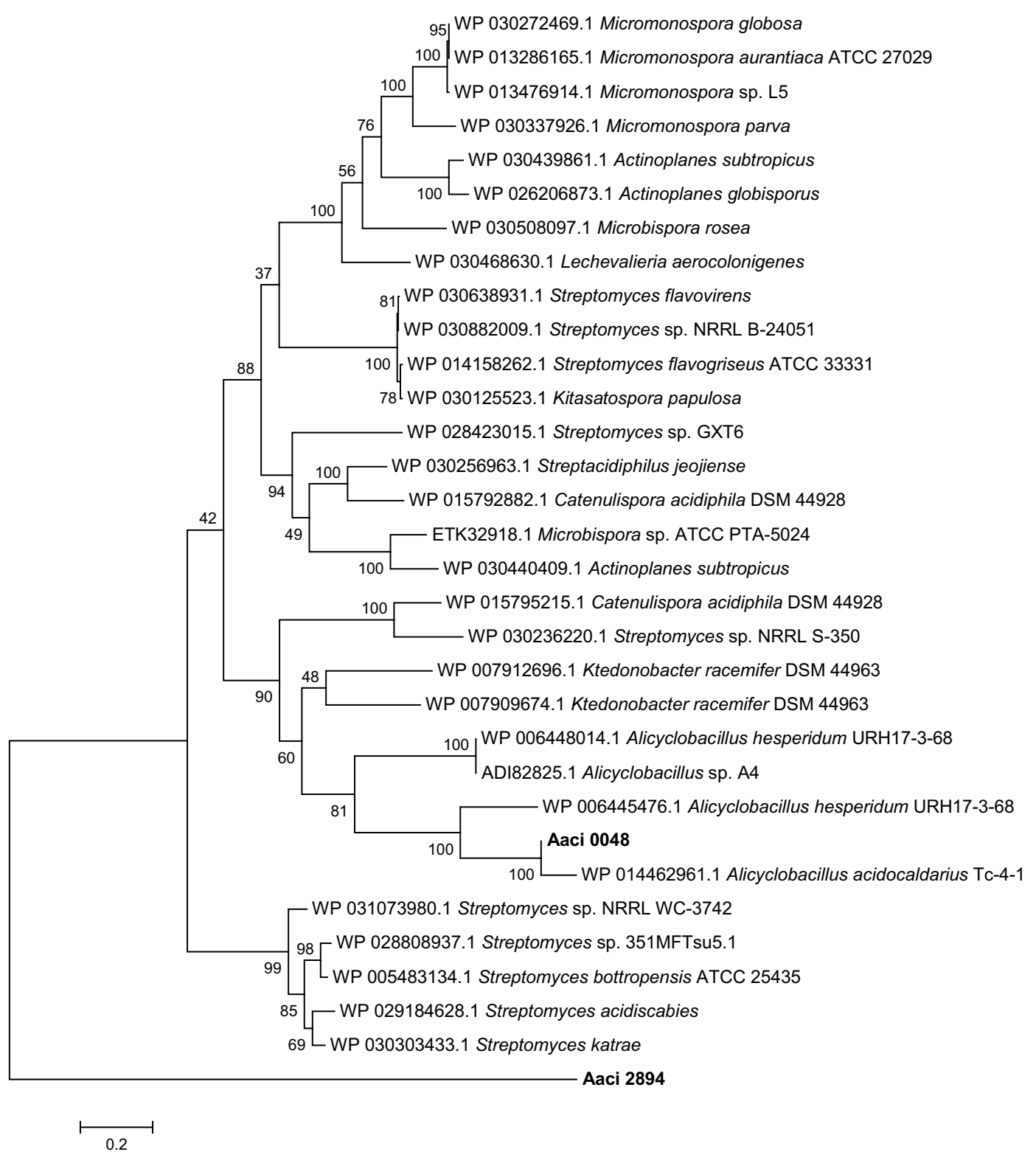

Fig. 6 Phylogenetic tree showing distance of a-L-arabinofuranosidase-like protein encoded by gene locus Aaci_0048 in A. acidocaldarius strain DSM 446 genome to similarly annotated genes in other Alicyclobacilli and a number of Actinomycetes. Each gene in tree is listed by accession number and bacterium carrying gene 
followed by fusion with a protein that supplied the endoglucanase and endoxylanase activity.

The putative protein product from genome locus Aaci_0060 is annotated as an $\alpha$-1,2-glucuronidase, which is most likely involved in hydrolysis of 4-O-methyl-D-glucuronic acid or glucuronic acid, both of which are found as modifications of the xylan backbone of WAX. Multidomain analysis of the protein product of Aaci_0060 supports the annotation as an $\alpha$-1,2-glucuronidase, and more detailed analysis shows the presence of C-terminal and middle domains (probable catalytic region) found in glycoside hydrolase family 67 proteins [44]. Aaci_0060 and Aaci_0048 may act in concert, since their loci are in the same gene neighborhood of the $A$. acidocaldarius genome; however, the relationship of transcription of these two genes has not been thoroughly studied. The proximity of these two genes appears to be conserved in a variety of Alicyclobacillus species, as demonstrated by comparing with the genomes of $A$. acidocaldarius subsp. acidocaldarius (Tc-4-1) and A. hesperidum URH17-3-68 (Fig. 7).

Phylogenetic analysis of the protein encoded by Aaci_0060 indicates relatedness to proteins from a number of other cellulolytic bacteria found in the phylum Firmicutes (Fig. 8). This protein from A. acidocaldarius shows greater than $50 \%$ homology to proteins that have been annotated as $\alpha$-glucuronidases in both aerobic and anaerobic bacteria in the genera Bacillus, Clostridium, Paenibacillus, Geobacillus, and Thermoanaerobacterium.

Regulation of gene loci Aaci_0786, Aaci_0789, and Aaci_0797 was also stimulated during this experiment. The first of these genes, Aaci_0786, has been annotated as a glycoside hydrolase clan GH-D protein, specifically an $\alpha$-galactosidase. A conserved domain comparison with other glycoside hydrolases in GenBank indicates specific hits to melibiase, with nonspecific hits to glycoside hydrolase family 31 (GH31) enzymes. Enzymes in the GH31 superfamily are present in all three domains of life, and activities include $\alpha$-glucosidase, $\alpha$-xylosidase, 6- $\alpha$-glucosyltransferase, 3 - $\alpha$-isomaltosyltransferase, and $\alpha-1,4$-glucan lyase. While this enzyme has been annotated as an $\alpha$-galactosidase, and could be involved in removal of galactose from the xylan backbone of WAX, expression of this enzyme during growth on WAX may also indicate $\alpha$-xylosidase activity.

Protein sequence analysis and classification (IPR013781) of Aaci_0789 indicates the presence of a catalytic TIM beta/alpha barrel common to many different families of glycoside hydrolases. This protein is greater than $50 \%$ identical with hypothetical proteins containing glycoside hydrolase catalytic domains found in other species of Alicyclobacillus. The proposed protein product for Aaci_0789 shows homology to an endo- $\beta$-1,4-mannanase that was characterized in Alicyclobacillus species A4 and A. acidocaldarius strains Tc-4-1 and Tc-12-31 [26, 45] (Fig. 9). The glycoside hydrolase encoded by this gene locus also demonstrates up to $50 \%$ homology to endo$\beta-1,4$-xylanases from a number of other Firmicutes, as well as hypothetical proteins from Firmicutes known to degrade xylan. In silico analysis of this gene along with expression results indicate a possible broad substrate range for this enzyme that would include mannose- and xylose-containing polysaccharides.

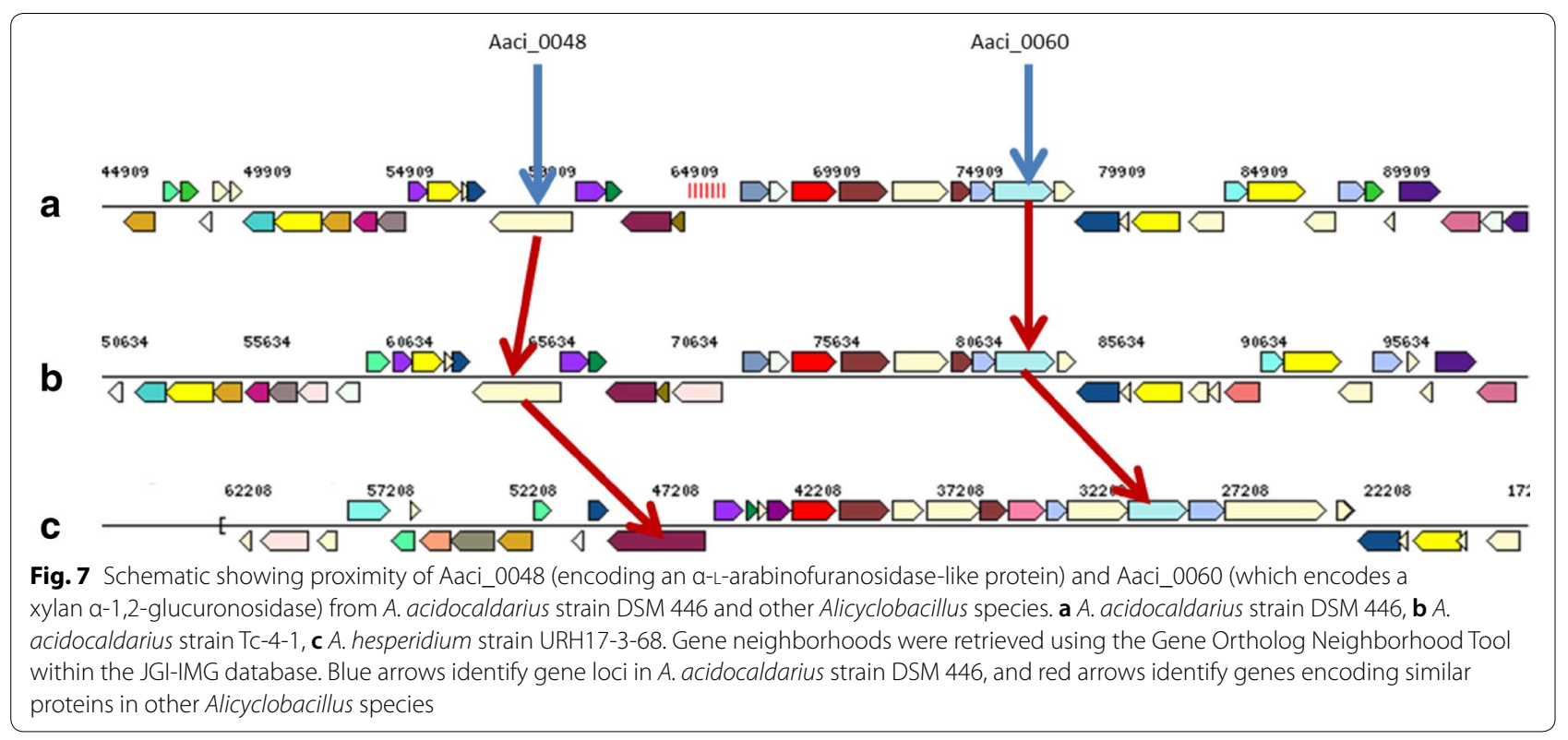




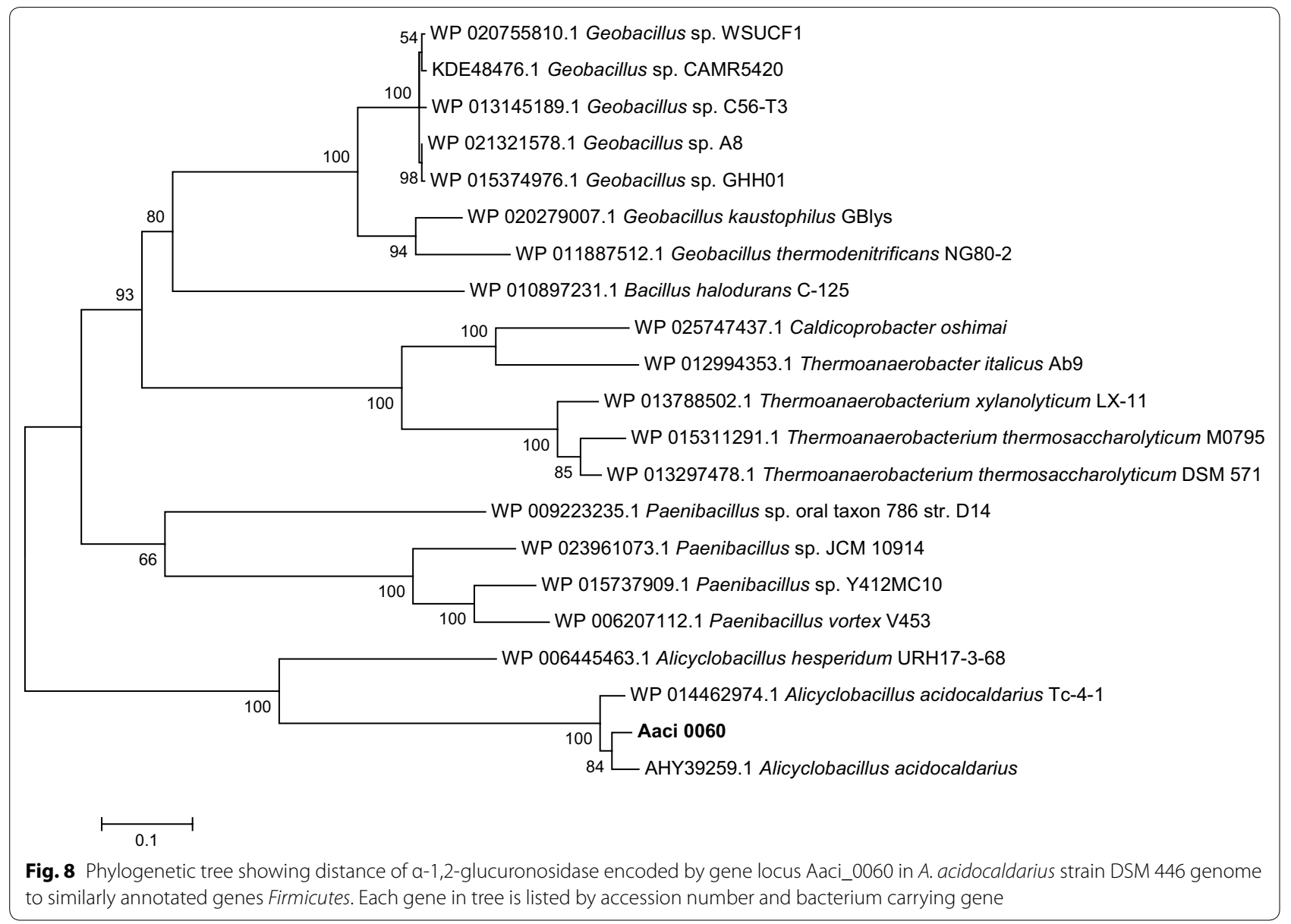

The final gene locus in this group, Aaci_0797, has been annotated as a glycoside hydrolase family 4 , $\alpha$-galactosidase. The protein encoded by Aaci_0797 is $99 \%$ identical to a $\beta$-galactosidase cloned from $\mathrm{A}$. acidocaldarius [19]. This recombinant enzyme hydrolyzed $o$-nitrophenyl- $\beta$-D-galactopyranoside and $o$-nitrophenyl$\beta$-D-fucopyranoside, but did not catalyze hydrolysis of $o$-nitrophenyl- $\beta$-D-glucopyranoside, $o$-nitrophenyl- $\beta$-Dxylopyranoside, or 0 -nitrophenyl- $\beta$-D-arabinopyranoside. These results indicate that Aaci_0797 is likely a $\beta$-galactosidase active toward galactose moieties on side chains of the WAX. Aaci_0797 also has greater than 70\% homology to $\alpha$-galactosidase from a number of other Gram-positive bacteria, including numerous species of Paenibacillus.

Arrangement of the genes encoding the glycoside hydrolase clan GH-D (Aaci_0786) and the hypothetical protein containing a glycoside hydrolase catalytic domain (Aaci_0789) are nearly identical in A. acidocaldarius subsp. acidocaldarius (DSM 446), A. acidocaldarius subsp. acidocaldarius (Tc-4-1), and $A$. hesperidum URH17-3-68 (Fig. 10). However, this gene arrangement is not conserved in A. herbarius DSM 12609. DSM 446 appears to have a cassette containing the glycoside hydrolase family $4 \alpha$-galactosidase (Aaci_0797), genes encoding ABC-transporter components (Aaci_0794-0796), and a LacI family transcriptional regulator (Aaci_0793) that is not present in the Tc-4-1 genome. Two $\beta$-galactosidase genes can be found in the Tc-4-1 genome, but translated protein sequences show low homology to Aaci_0797, indicating that Tc-4-1 may lack $\alpha$-galactosidase activity.

Annotation within the JGI-IMG/M categorizes Aaci_1218 with a product name of a glycoside hydrolase family 2 TIM barrel. Analysis of the protein sequence showed no signal sequence, indicating activity inside the cell. Gene Ontology (GO:0004565), clusters of orthologous groups (COG3250), and KEGG Orthology (KO:01190) indicate that this protein may be a $\beta$-galactosidase/ $\beta$-glucuronidase. This 1041 amino acid protein shows the highest homology to glycoside hydrolases found in other Bacilli. This enzyme most likely acts on either galactose or 4-O-methyl-D-glucuronic acid side chains found in WAX. These results indicate that $A$. acidocaldarius was expressing genes related to side 


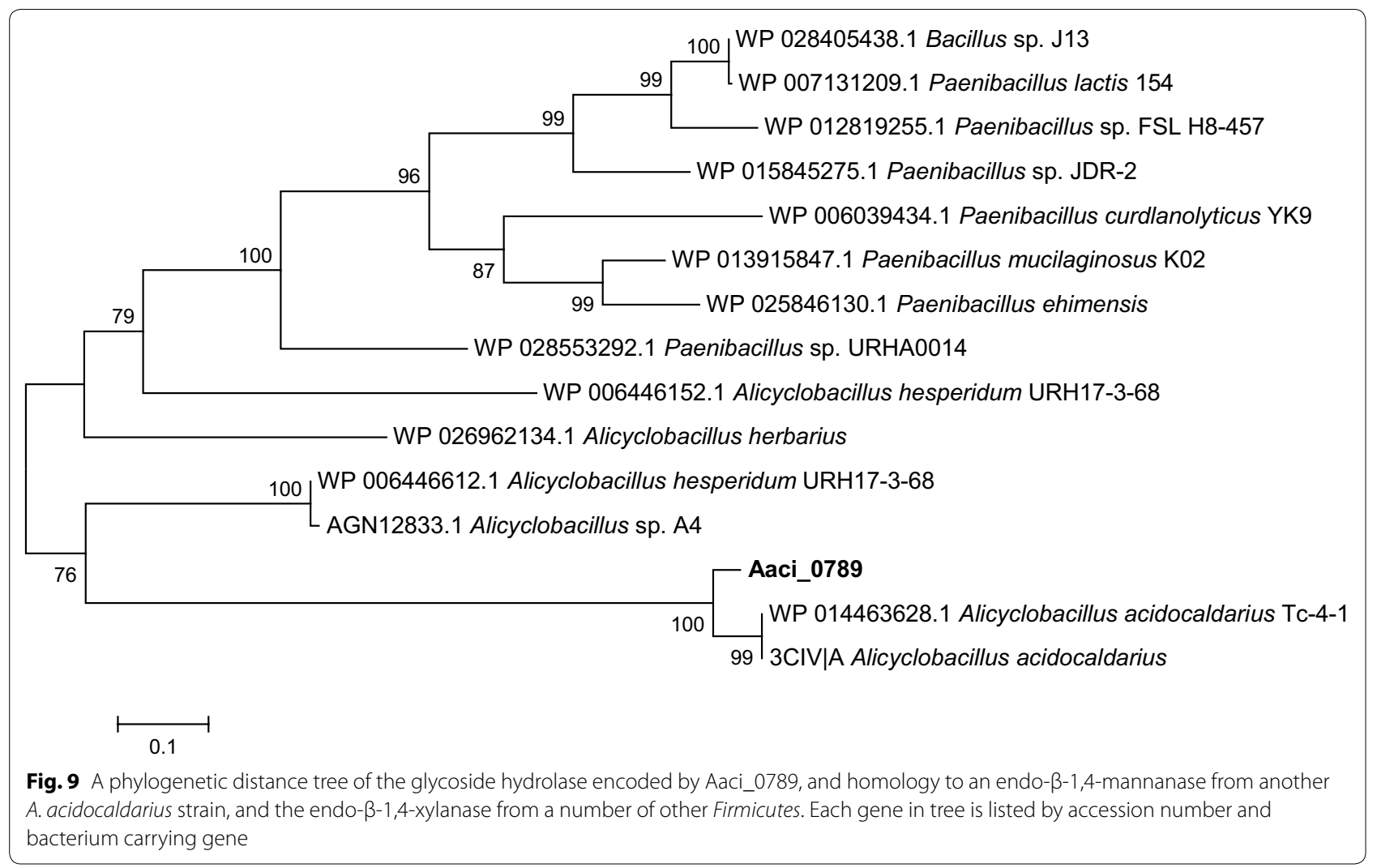

a
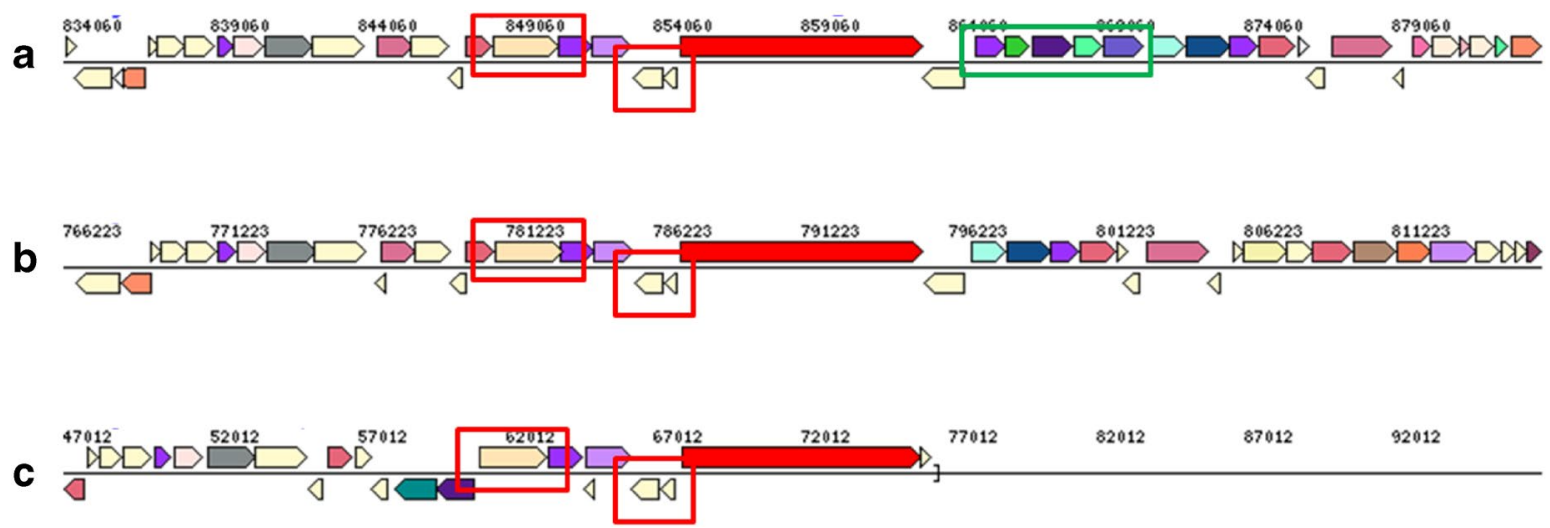

Fig. 10 Genome neighborhood showing conserved genes encoding glycoside hydrolases (red boxes) in two A. acidocaldarius species, and A. hesperidum species URH17-3-68. Green box indicates genes for a glycoside hydrolase, an ABC-transporter and a transcriptional regulator, which are present in the A. acidocaldarius strain DSM 446 genome but not in A. acidocaldarius strain Tc-4-1. a A. acidocaldarius subsp. acidocaldarius (DSM 446), b A. acidocaldarius subsp. acidocaldarius (Tc-4-1), and c A. hesperidum URH17-3-68

chain hydrolysis of the WAX, which were regulated upon addition of xylose. Aaci_1218 appears to be in an apparent operon with genes for an ABC-transport system and a LacI transcriptional regulator, all of which were highly downregulated.

The 453 amino acid $A$. acidocaldarius protein encoded by Aaci_1895 has greater than $60 \%$ homology to $\beta$-galactosidase/ $\beta$-glucosidase enzymes found in other Firmicutes, namely numerous species of Thermoanaerobacter (Fig. 11). Di Lauro et al. [6] characterized a recombinant $\beta$-glycosidase from $A$. acidocaldarius that showed wide substrate specificity and was able to hydrolyze $\beta$-Dgluco-, -galacto-, and fucosides. The protein encoded by Aaci_1895 is $98 \%$ identical to the characterized 


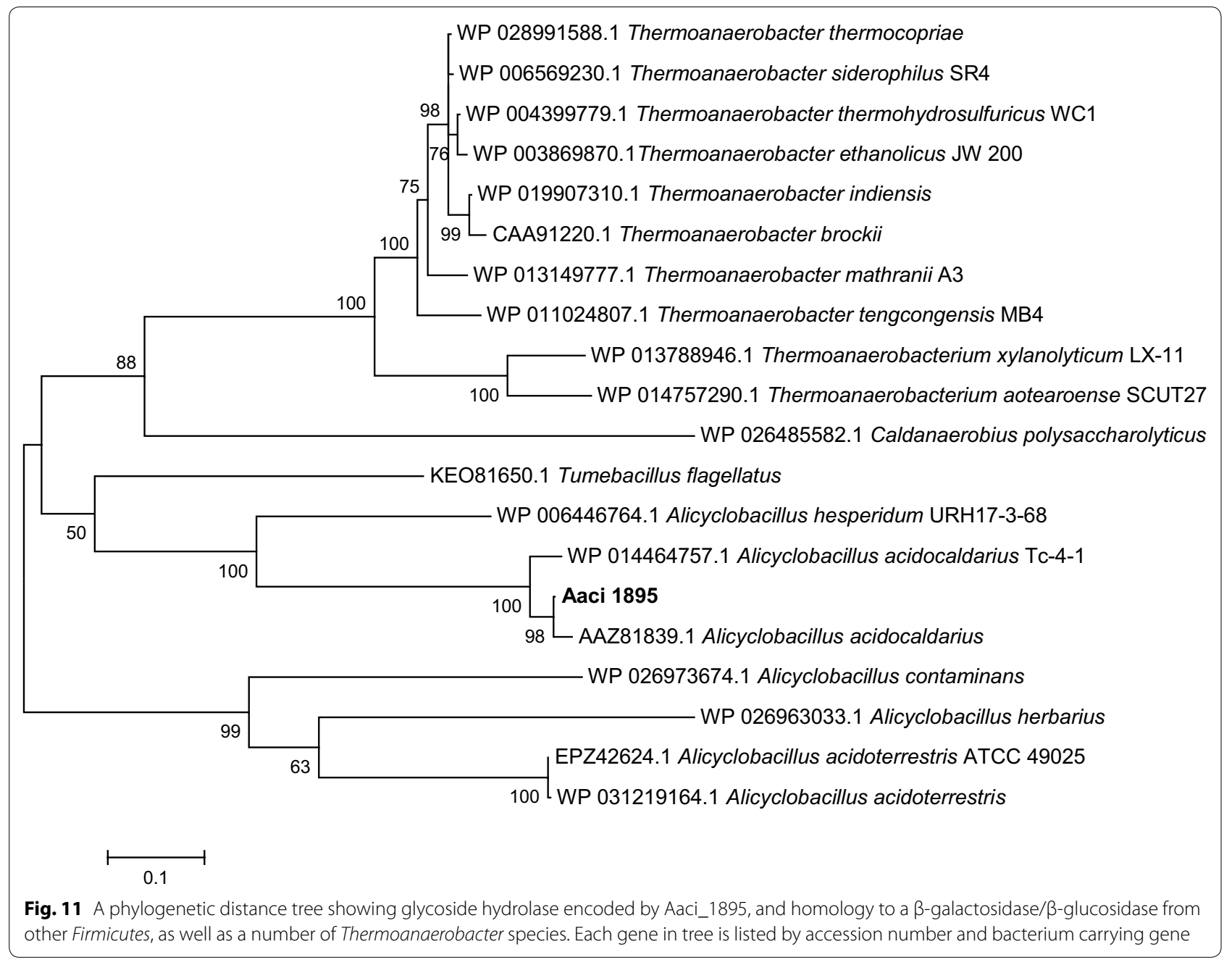

$\beta$-glycosidase, and thus is likely the same protein. Like many other glycoside hydrolase encoding genes in the A. acidocaldarius genome, Aaci_1895 is arranged in an operon with an $\mathrm{ABC}$-type transport system; however, this specific ABC-type transporter has been annotated as an oligopeptide/dipeptide transporter. Utilization of oligopeptide/dipeptide $\mathrm{ABC}$-type transporters for carbohydrate transport is not uncommon in other thermophilic lignocellulose-degrading bacteria, including Thermotoga maritima and Caldicellulosiruptor saccharolyticus [46, 47]. This gene arrangement, including the oligopeptide/ dipeptide $\mathrm{ABC}$-type transporter genes, is also common in a number of Thermoanaerobacter species. The primary difference between $A$. acidocaldarius and the Thermoanaerobacter species is the presence of an additional gene, which encodes a family 2 glycoside hydrolase, situated between the $\beta$-galactosidase/ $\beta$-glucosidase and the transporter genes (Fig. 12). The family 2 glycoside hydrolase gene encoded in the Thermoanaerobacter genomes may have a similar function to the family 2 glycoside hydrolase encoded by Aaci_1218, which was also highly downregulated in $A$. acidocaldarius, as discussed above. Comparing the family 2 glycoside hydrolase from Thermoanaerobacter mathranii to the $A$. acidocaldarius subsp. acidocaldarius DSM 446 genome yielded the closest homology to Aaci_1218 $(E$ value $=9 \mathrm{e}-10)$; other proteins had $E$ values greater than 1 .

Domain analysis of the 537 amino acid protein encoded by Aaci_2475 indicates that the enzyme may have endoglucanase activity, but since it appears to be active on WAX, the enzyme may have an expanded substrate range, and act on substrates other than cellulose or cellobiose. Endoglucanases with broad substrate specificity, including activity toward xylans, have been demonstrated in other thermophiles, including Pyrococcus furiosus and T. maritima [48, 49]. The glycoside hydrolase encoded by Aaci_2475 is next to an ABC-type oligopeptide transport system, which was also highly downregulated when xylose was added, as was the case with Aaci_1895 and neighboring genes. Analysis of the gene neighborhood 


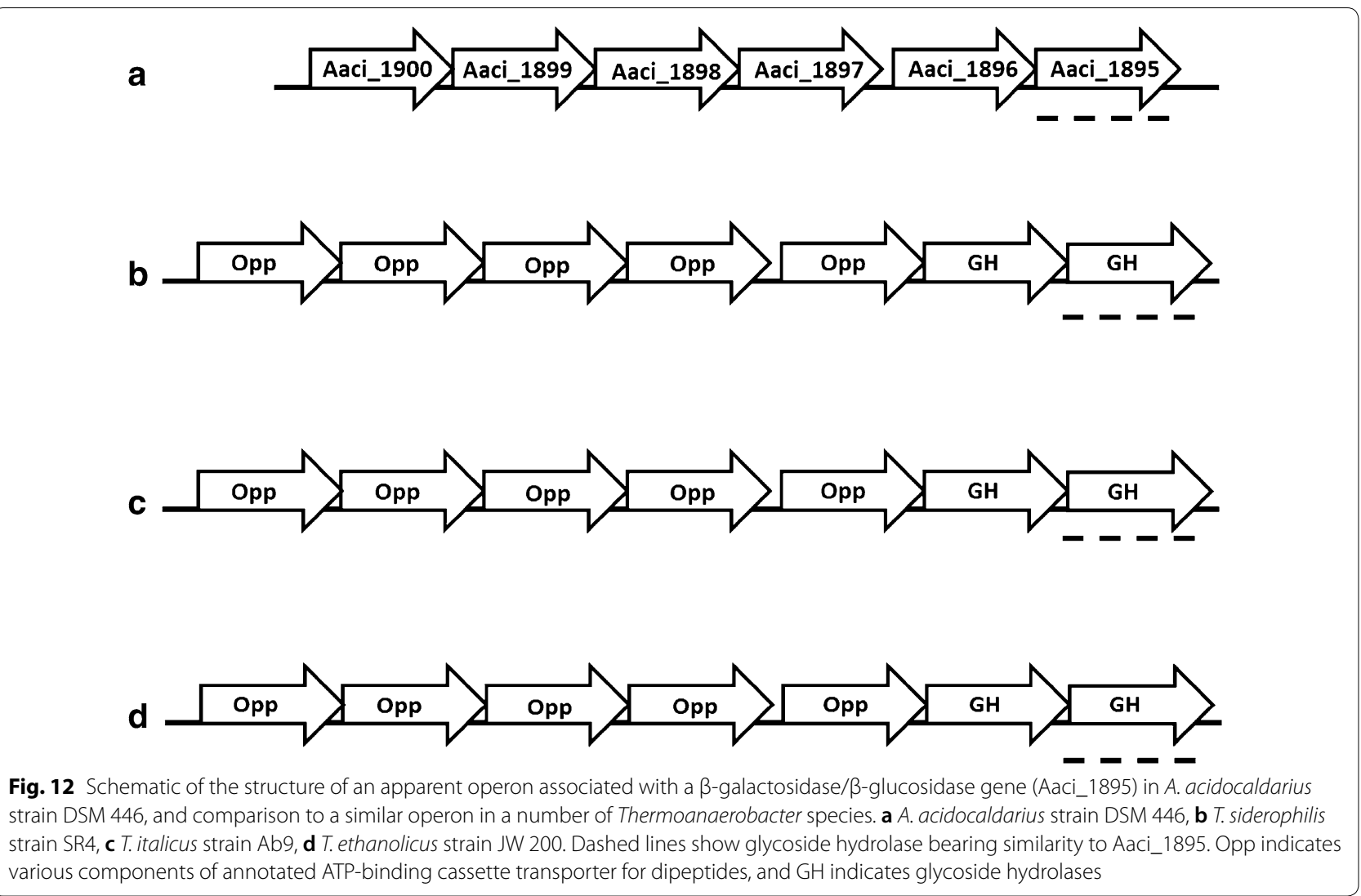

where this family 9 glycoside hydrolase is found indicates that this apparent operon structure is common in numerous Alicyclobacillus species, including A. acidocaldarius subsp. acidocaldarius (DSM 446), A. acidocaldarius subsp. acidocaldarius (Tc-4-1), and A. hesperidum URH17-3-68 (Fig. 13). Xylan-hydrolyzing activity by an endoglucanase is not unprecedented; Hall et al. [50] characterized an endoglucanase from Clostridium thermocellum with xylanase activity. More recently, a bifunctional xylanase-glucanase from Paenibacillus sp. Strain E18 was characterized and showed activity toward xylan and glucan [51]. Likewise, bifunctional xylanase/endoglucanase enzymes have been generated from the metagenome libraries from a yak and bovine rumen microbial community and showed activity toward a variety of xylans and glucans $[52,53]$.

Aaci_2630 encodes a glycoside hydrolase family 3 domain protein with $\beta$-glucosidase or $\beta$-xylosidase activity. Regulation during growth on WAX further supports the possibility of $\beta$-xylosidase activity. Homology analysis of Aaci_2630 to other $\beta$-xylosidases genes deposited in the National Center for Biotechnology Information (NCBI) database shows greater than $50 \%$ similarity to family 3 glycoside hydrolases from other thermophilic, lignocellulose-degrading bacteria, including Thermoanaerobacter, Caldicellulosiruptor and Thermotoga species (Fig. 14). This proposed $\beta$-xylosidase also has $\sim 60 \%$ identity with three enzymes expressed from recombinant DNA showing specificity toward xylo-oligosaccharides for which activity assays have been performed [54-56]. Xyl3A from Caldanaerobius polysaccharolyticus demonstrated both $\beta$-glucosidase and $\beta$-xylosidase activity, but activity toward xylooligosaccharides was the highest [55]. Enzymes that showed homology to Aaci_2630 from two species of Thermoanaerobacter have also been characterized as $\beta$-xylosidases. A bifunctional xylosidase-arabinosidase (XarB) from $T$. ethanolicus JW200 demonstrated activity toward a variety of substrates, but the highest activity/affinity was toward xylo- and arabinopyranoside molecules [56]. Similarly, a xylodextrin-hydrolyzing xylo- $\beta$-glucosidase from T. brockii was shown to possess both $\beta$-glucosidase and $\beta$-xylosidase activity [54]. Homology of Aaci_2630 with these other proteins that have demonstrated $\beta$-xylosidase activity and the downregulation in these experiments support classification of the encoded enzyme as a $\beta$-xylosidase.

A section of the $A$. acidocaldarius genome from gene locus Aaci_2868 through Aaci_2894 appears to be a 'hot spot' for glycoside hydrolase activity because 6 of the 
a

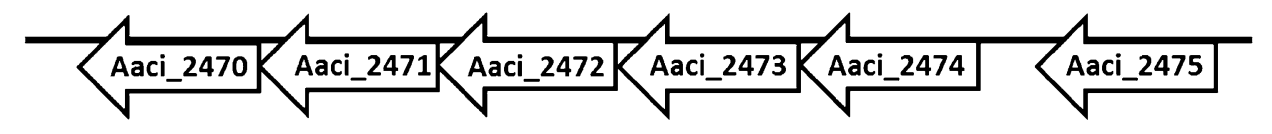

b

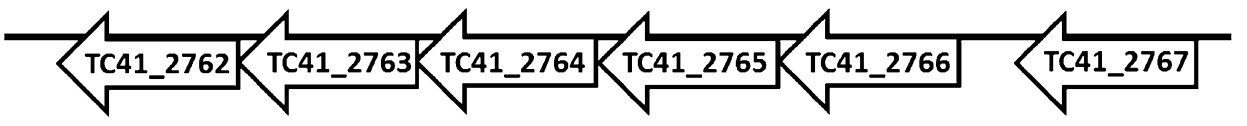

C

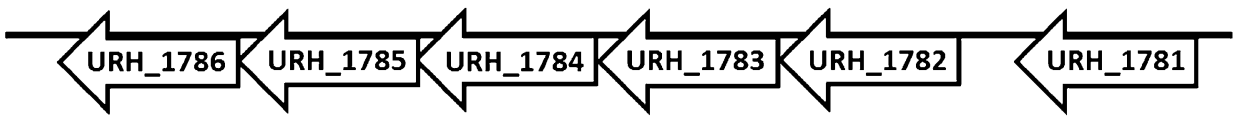

d

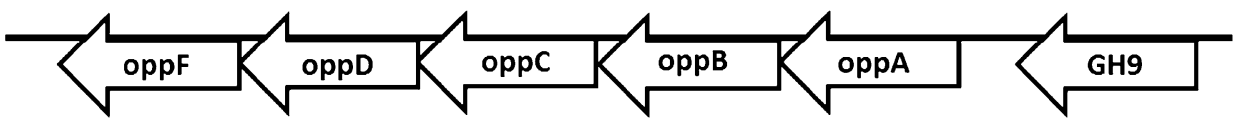

Fig. 13 Schematic showing apparent operon structure associated with Aaci_2475, a gene encoding an endoglucanase, and comparison to other Alicyclobacillus species. a A. acidocaldarius strain DSM 446, b A. acidocaldarius strain Tc-4-1, c A. hesperidum strain URH17-3-68, d general operon structure showing proposed components associated with gene loci for each bacterium

19 glycoside hydrolase encoding genes in A. acidocaldarius are found in this region (Fig. 15). Annotation in this region indicates genes encoding both cellulose- and hemicellulose-hydrolyzing enzymes. Half of the glycoside hydrolase genes were regulated during the experiment, maintaining the trend of higher regulation when xylose was added to the exponentially growing culture of $A$. acidocaldarius.

The translated protein from Aaci_2874 shows over 99\% homology to an enzyme cloned from $A$. acidocaldarius that had $\alpha$-amylase and pullulanase catalytic activity [20]. A thermoacidophilic $\alpha$-amylase expressed from Alicyclobacillus sp. A4 which showed $65 \%$ identity with the protein encoded by Aaci_2874 also showed high activity toward starch compounds, but the substrate range of the enzyme was not determined [57]. Aaci_2874 is located in what may be an operon containing two other glycoside hydrolases-Aaci_2868 and Aaci_2869-neither of which was regulated to the extent of Aaci_2874 when xylose was added. Since there have been no reports of bifunctional $\alpha$-amylases, the relationship of this enzyme to WAX depolymerization is not known, but regulation of this gene when $A$. acidocaldarius was grown on WAX indicates that this enzyme has adapted for hydrolysis of xylan polysaccharides.
During metabolism of WAX, $\alpha$-arabinofuranosidase catalyzes the hydrolysis of terminal $\alpha$-arabinofuranosidic linkages to xylose residues in the xylan backbone. Gene locus Aaci_2894 encodes a putative $\alpha$-arabinofuranosidase that is associated with an operon involved in arabinose metabolism, for which all genes were downregulated, regardless of whether xylose or glucose was used as the inducing sugar. The protein product from this gene has greater than $60 \%$ homology to $\alpha$-arabinofuranosidases found in a number of Gram-positive bacteria, including Geobacillus, Paenibacillus, and Thermoanaerobacterium. As with other genes previously discussed, this or similar operons appear to be conserved among Alicyclobacillus species.

Domain analysis for the protein encoded by Aaci_2887 is consistent with $\alpha$-xylosidase/ $\alpha$-glucosidase activity, which consists of cleaving the terminal carbohydrate moiety from a variety of substrates. Since the gene was upregulated upon the addition of xylose, this 779-amino acid glycoside hydrolase may be involved in xylose metabolism, or even cleaving xylose that is linked to other sugars present in WAX. Comparison to other genes in the NCBI database indicates that Aaci_2887 is $50 \%$ identical to $\alpha$-xylosidase/ $\alpha$-glucosidase enzymes in other Gram-positive lignocellulose utilizing bacteria, 

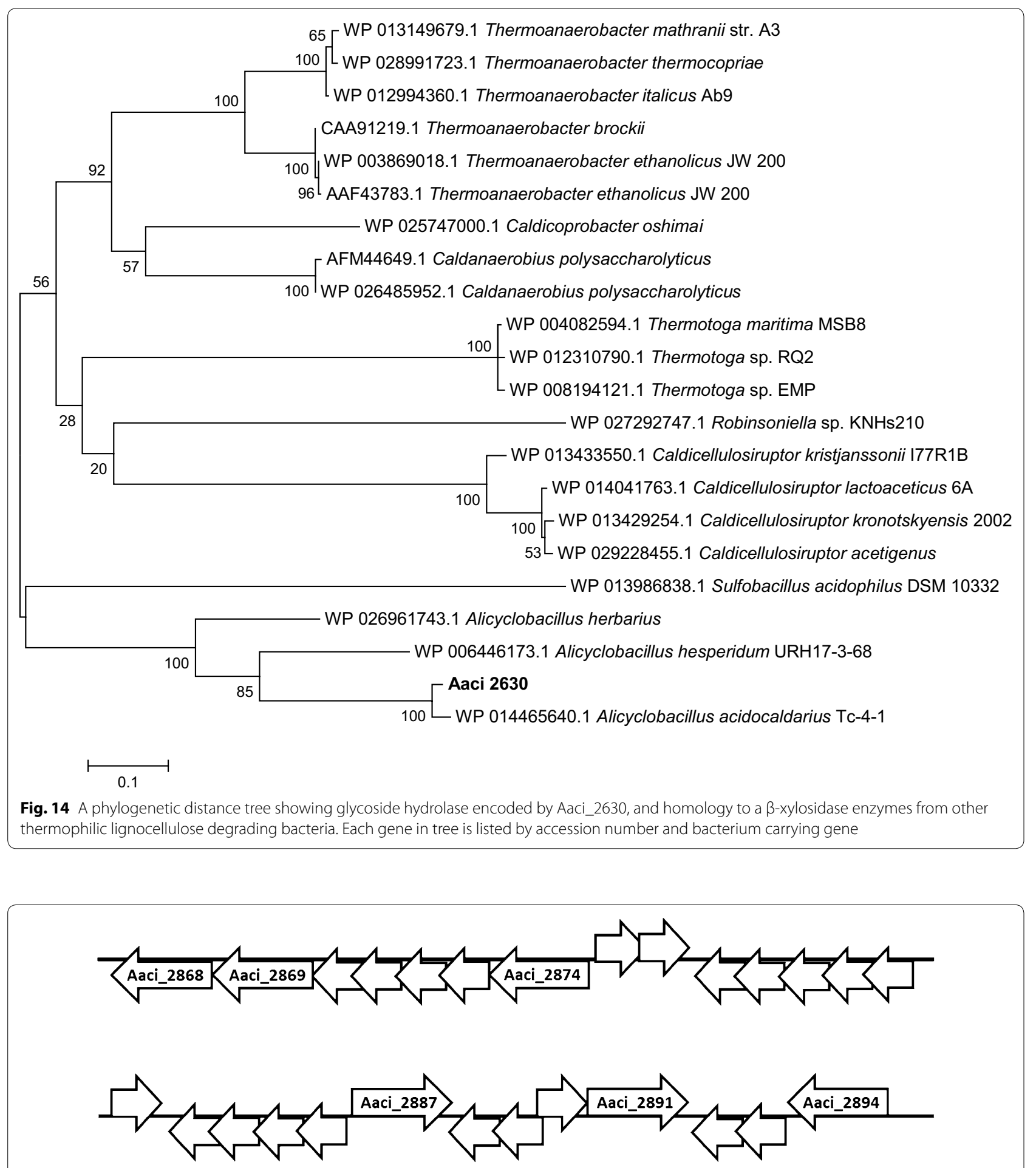

Fig. 15 Schematic showing glycoside hydrolase genes from the A. acidocaldarius strain DSM 446 genome spanning DNA coordinates 2,926,031 to $2,962,624$. Short arrows without gene locus are shown to demonstrate the numbers of genes between each glycoside hydrolase and directionality of genes 


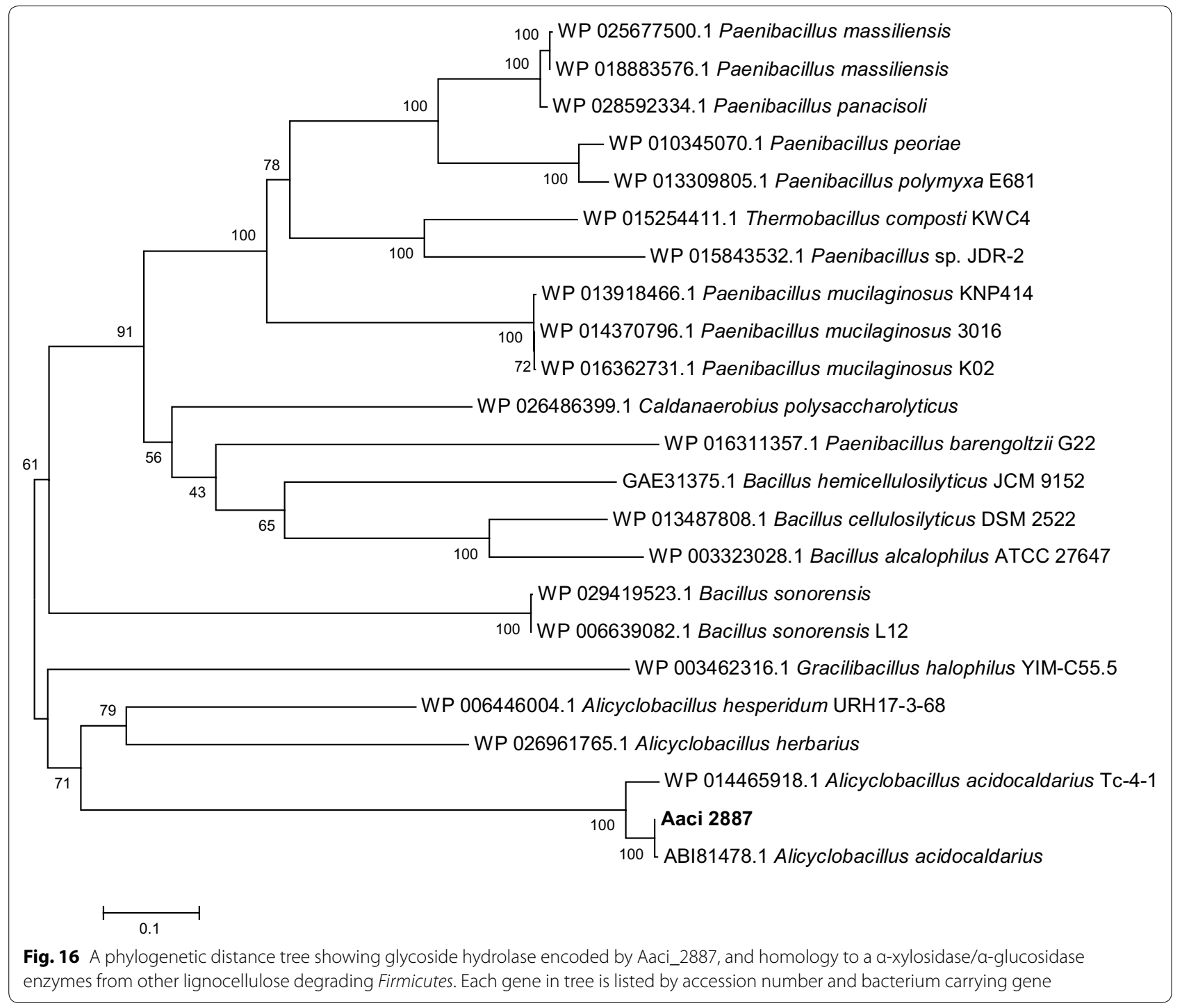

including numerous Paenibacillus and Clostridium species (Fig. 16). The protein sequence from Aaci_2887 is 99\% identical to an enzyme expressed from recombinant DNA, thermostable $\alpha$-glucosidase (ABI81478.1) from $A$. acidocaldarius that was deposited into GenBank, but no information on enzyme activity or specificity has been published. Other glycoside hydrolase family 31 enzymes that display $\alpha$-xylosidase activity have been found in the Crenarchaeota Sulfolobus solfataricus (i.e., XylS) and the Gram-positive Cellovibrio japonicus [58, 59].

\section{Conclusions}

In general, $A$. acidocaldarius appears to have enzymes necessary for the efficient depolymerization of WAX. Likewise, these enzymes were expressed when $\mathrm{A}$. acidocaldarius strain ATCC27009 was grown on WAX. A number of the enzymes also appear to have a broad substrate range, allowing for hydrolysis of various bonds present in WAX even though the annotated activity of the enzyme would not predict this hydrolysis.

Glycoside hydrolases, for the most part, appear to be found in clusters, throughout the $A$. acidocaldarius genome. Not all of the glycoside hydrolase genes found at loci within these clusters were regulated during the experiment, indicating that a specific subset of the 19 glycoside hydrolase genes found in $A$. acidocaldarius were used during metabolism of WAX. While specific functions of the glycoside hydrolases was not tested as part of the research discussed, many of the glycoside hydrolases found in the $A$. acidocaldarius Type Strain appear to have a broader substrate range than represented by the glycoside hydrolase family in which the enzymes were categorized. 


\section{Materials and methods} Inoculum development

Alicyclobacillus acidocaldarius ATCC 27009 was purchased from the American Type Culture Collection (ATCC) and used for all experiments. Chemostat inoculum was prepared by inoculating $1 \mathrm{~mL}$ of the frozen stock into $25 \mathrm{~mL}$ of Modified 402 Medium, which contained the following (g/L): $\left(\mathrm{NH}_{4}\right)_{2} \mathrm{SO}_{4}$ (1.3), $\mathrm{Fe}(\mathrm{III})$ EDTA (0.047), $\mathrm{CaCl}_{2} \cdot 2 \mathrm{H}_{2} \mathrm{O}(0.07), \mathrm{MgSO}_{4} \cdot 7 \mathrm{H}_{2} \mathrm{O}$ (0.25), $\mathrm{KH}_{2} \mathrm{PO}_{4}$ (3.0), and xylose (4.0). In addition, $1 \mathrm{~mL}$ of a mineral (solutions $\mathrm{A}$ and $\mathrm{B}$ ) and vitamin stock (solution C) were added. Solution A contained (g/L): $\mathrm{MgCl}_{2}$ (25), $\mathrm{CaCl}_{2} \cdot 2 \mathrm{H}_{2} \mathrm{O}$ (6.6), $\mathrm{H}_{3} \mathrm{BO}_{3}$ (0.58), $\mathrm{FeCl}_{3} \cdot 6 \mathrm{H}_{2} \mathrm{O}$ (5), $\mathrm{Co}\left(\mathrm{NO}_{3}\right)_{2} \cdot 6 \mathrm{H}_{2} \mathrm{O}(0.05), \mathrm{NiCl}_{2} \cdot 6 \mathrm{H}_{2} \mathrm{O}(0.02)$. Solution $\mathrm{B}$ contained (g/L): $\mathrm{MnSO}_{4} \cdot \mathrm{H}_{2} \mathrm{O}(2.0), \mathrm{ZnSO}_{4} \cdot 7 \mathrm{H}_{2} \mathrm{O}(0.5)$, $\mathrm{CuSO}_{4} \cdot 5 \mathrm{H}_{2} \mathrm{O}$ (0.15), $\mathrm{Na}_{2} \mathrm{MoO}_{4} \cdot 2 \mathrm{H}_{2} \mathrm{O}$ (0.025). Solution $\mathrm{C}$ contained $(\mathrm{g} / \mathrm{L})$ : pyridoxine hydrochloride (0.08), folic acid $(0.012)$, thiamine hydrochloride $(0.13)$, riboflavin (0.042), nicotinamide (0.084), $p$-aminobenzoate (0.088), biotin (0.01), cyanocobalamin (0.0004), D-pantothenic acid, calcium salt (0.086), myo-inositol (0.021), choline bromide (0.053), orotic acid, sodium salt (0.021), and spermidine (0.1). Base medium was autoclaved $\left(121^{\circ} \mathrm{C}\right.$, $20 \mathrm{psi}$ ) for $30 \mathrm{~min}$ prior to use; $\mathrm{KH}_{2} \mathrm{PO}_{4}$ solution was adjusted to $\mathrm{pH} 4.0$, autoclaved separately, and added once the base medium had cooled. The $25 \mathrm{~mL} A$. acidocaldarius culture was grown overnight and then used to inoculate $250 \mathrm{~mL}$ of Modified 402 Medium containing $4 \mathrm{~g} / \mathrm{L}$ xylose. This overnight culture grown at $\mathrm{pH} 4$ at a temperature of $60{ }^{\circ} \mathrm{C}$ was then used to inoculate the chemostat.

\section{Chemostat studies}

Experiments were performed in a BioFlo 3000 chemostat system (New Brunswick Scientific, Enfield, CT). Medium was added to the reactor, and the entire reactor was autoclaved at $121{ }^{\circ} \mathrm{C}$, and a pressure of 20 psi for $1 \mathrm{~h}$. WAX (Megazyme, Inc.) was prepared by first wetting $2 \mathrm{~g}$ with $95 \%$ ethanol. Once in a slurry, $190 \mathrm{~mL}$ of sterile distilled water ( $\mathrm{pH} 4.0)$ was added, and the solution was heated for $30 \mathrm{~min}$ to evaporate residual ethanol. Pre-dissolved WAX (2 g/190 mL medium) was then added to the $2 \mathrm{~L}$ of Modified 402 Medium in the chemostat, giving a final WAX concentration of $1 \mathrm{~g} / \mathrm{L}$. The chemostat was run in batch mode and the temperature was held at $60{ }^{\circ} \mathrm{C}$ and the $\mathrm{pH}$ of the growth medium was automatically controlled to 4.0 using the addition of $1 \mathrm{~N} \mathrm{NaOH}$. To ensure that the cultures were not oxygen limited, dissolved oxygen was controlled to $10 \%$.

Once the $A$. acidocaldarius culture reached an $\mathrm{OD}_{600}$ of 0.5 while growing on WAX, a sample was taken for RNA extraction, glucose or xylose was added at a concentration of $2 \mathrm{~g} / \mathrm{L}$, and then a second sample was immediately (within $5 \mathrm{~min}$ ) taken for RNA extraction. Three biological replicates for each condition were performed.

\section{Isolation of total RNA}

Samples were taken from the chemostat, and RNA was stabilized using RNA Protect Bacteria Reagent (Qiagen, Valencia, CA), followed by flash freezing of the cell pellet in liquid nitrogen and storage at $-80{ }^{\circ} \mathrm{C}$. Total RNA was extracted from the $A$. acidocaldarius cells using an RNeasy Midi Kit (Qiagen, Valencia, CA) with slight modification of the manufacturer's protocol. A. acidocaldarius cells were thawed, and lysis was accomplished by adding $200 \mu \mathrm{L}$ of Tris-EDTA buffer containing $15 \mathrm{mg} /$ $\mathrm{mL}$ lysozyme and $0.1 \mathrm{mg} / \mathrm{mL}$ proteinase K. Samples were vortexed for $10 \mathrm{~s}$ and then incubated at room temperature for 15 min with shaking. Manufacturer's instructions supplied with the kit were followed up to elution of the RNA. To increase RNA yield, the flow through was reapplied to the spin filter and centrifuged. Residual DNA in the samples was removed by treatment with Ambion TURBO DNA-free kit (Life Technologies, Grand Island, NY). RNA was purified to remove compounds that might interfere with cDNA synthesis and concentrated using ethanol precipitation. To inhibit RNA degradation during storage, $1 \mu \mathrm{L}$ of Ambion Superase-In RNase Inhibitor (Life Technologies, Grand Island, NY) was added. RNA concentration and purity were determined using a NanoDrop ND-1000 spectrophotometer (Thermo Scientific, Wilmington, DE). RNA integrity was determined using an RNA Nano Chip Kit run on an Agilent 2100 Bioanalyzer (Agilent, Santa Clara, CA).

\section{Synthesis of cDNA}

Double-stranded cDNA was synthesized from total RNA using the Invitrogen Superscript Double-Stranded cDNA Synthesis Kit (Life Technologies, Grand Island, NY) according to manufacturer's instructions, with the following modifications. Following cDNA synthesis, residual RNA was degraded by adding RNase A, followed by proteins removal using phenol:chloroform:isoamyl alcohol, and separation using Phase Lock Tubes (5 Prime, Inc., Gaithersburg, MD). cDNA in the aqueous phase was then precipitated and concentrated by ethanol precipitation. The pellet was dried and then resuspended in $20 \mu \mathrm{L}$ of DNase/RNase-Free water and allowed to solubilize overnight. cDNA concentration in each reaction was determined using a NanoDrop ND-1000 spectrophotometer (Thermo Scientific, Wilmington, DE). A DNA 7500 Chip Kit run on an Agilent 2100 Bioanalyzer (Agilent, Santa Clara, CA) was used to verify that most of the cDNA was $\geq 400 \mathrm{bp}$. 


\section{Microarray experiments and data analysis}

Microarrays were designed and synthesized by NimbleGen using their $4 \times 72 \mathrm{~K}$ Custom Gene Expression Array format from the complete genome sequence information for A. acidocaldarius ATCC 27009 (DSM 446). Seven probes, each $60 \mathrm{nt}$ long, were designed for each of the 3554 identified open reading frames in the genome, based on a genome sequence generated by Integrated Genomics, Inc for the Idaho National Laboratory. Each probe was synthesized on the microarray in triplicate. Control probes were also included to ensure that there was no intra-quadrant contamination during the hybridization process.

One color cDNA labeling using Cy3, hybridization to the $A$. acidocaldarius microarrays, array imaging, and initial analysis of the array data were performed by NimbleGen. Data were normalized using Nimblescan software, which normalizes probe response using quantile normalization and gene calls generation using Robust Multichip Averaging (RMA) [60, 61]. Log $_{2}$-transformed RMA data files were imported into ArrayStar 4 software (DNASTAR, Inc., Madison, WI), and the mean expression levels of three replicate arrays for each condition were considered. For comparison of gene expression, statistical significance was determined with a Bonferroni corrected moderate $t$ test, and only genes where expression had greater than $95 \%$ confidence $(p \leq 0.05)$ were considered significant.

Comparative analysis of the $A$. acidocaldarius genome was performed using the Integrated Microbial Genomes feature within the Joint Genome Institute [62]. Homology determinations for $A$. acidocaldarius proteins were accomplished using the Basic Local Alignment Search Tool (BLAST) for protein sequences using the 'blastp' algorithm [63, 64]. The nonredundant protein sequence database was used for searches, and uncultured and environmental sample sequences were excluded from the search. Phylogenetic trees comparing protein sequences were generated using the Molecular Evolutionary Genetics Analysis (MEGA6) software program [65]. Protein sequences were aligned using the MUSCLE program within MEGA6 [66, 67]. Phylogenetic reconstruction was accomplished using the maximum likelihood statistical method, and distances between sequences were determined using 1000 bootstrap replicates.

\footnotetext{
Abbreviations

WAX: wheat arabinoxylan; NCBI: National Center for Biotechnology Information; CCR: carbon catabolite repression; PTS: phosphotransferase system; ATP: adenosine triphosphate; ABC: ATP binding cassette; ATCC: American Type Culture Collection; CE: carbohydrate esterase; DSM: Deutsche Sammlung von Mikroorganismen; DNA: deoxyribonucleic acid; KEGG: Kyoto Encyclopedia of Genes and Genomes; JGI: Joint Genome Institute; IMG: Integrated Microbial Genomes; GO: gene ontology; COG: cluster of orthologous genes; BLAST: Basic
}

Local Alignment Search Tool; GH: glycoside hydrolase; RMA: Robust Multichip Averaging; MEGA: Molecular Evolutionary Genetics Alignment; MUSCLE: Multiple sequence comparison by log-expectation; cDNA: complementary DNA; RNA: ribonucleic acid.

\section{Authors' contributions}

$\mathrm{BL}$ designed and performed the study, analyzed the data, and drafted the manuscript. WA, PS, and LD assisted in interpretation of data, provided direction for the studies, and revised the manuscript. All authors read and approved the final manuscript.

\section{Author details}

${ }^{1}$ Biological Systems Department, Idaho National Laboratory, P. O. Box 1625, Idaho Falls, ID 83415, USA. ${ }^{2}$ Department of Biological Sciences, Idaho State University, Campus Box 8007, Pocatello, ID 83209, USA. ${ }^{3}$ Department of Biology, New Mexico Institute of Mining and Technology, 801 Leroy PI, Socorro, NM 87801, USA. ${ }^{4}$ Present Address: Pacific Northwest National Laboratory, Energy and Environment Directorate, Richland, WA, USA.

\section{Acknowledgements}

This work was supported by the Idaho National Laboratory's Laboratory Directed Research and Development program under the Department of Energy Idaho Operations Office Contract DE-AC07-05ID14517.

\section{Competing interests}

The authors declare that they have no competing interests.

\section{Availability of data and materials}

The datasets generated and analyzed during the current study are available in the Gene Expression Omnibus (GEO) repository within NCBI.

\section{Consent for publication}

Not applicable.

Ethics approval and consent to participate

Not applicable.

\section{Funding}

Funding for the research was provided through the Idaho National Laboratory's Laboratory Directed Research and Development Program.

\section{Publisher's Note}

Springer Nature remains neutral with regard to jurisdictional claims in published maps and institutional affiliations.

Received: 7 August 2017 Accepted: 6 April 2018

Published online: 16 April 2018

\section{References}

1. Darland G, Brock TD. Bacillus acidocaldarius sp. nov., an acidophilic thermophilic spore-forming bacterium. J Gen Microbiol. 1971;67(1):9-15.

2. Wisotzkey J, Jurtshuk P Jr, Fox G, Deinhard G, Poralla K. Comparative sequence analyses on the 16S rRNA (rDNA) of Bacillus acidocaldarius, Bacillus acidoterrestris, and Bacillus cycloheptanicus and proposal for creation of a new genus, Alicyclobacillus gen. nov. Int J System Bacteriol. 1992;42:263-9.

3. Nicolaus B, Improta R, Manca MC, Lama L, Esposito E, Gambacorta A. Alicyclobacilli from an unexplored geothermal soil in Antarctica: mount Rittmann. Polar Biol. 1998;19(2):133-41.

4. Goto K, Mochida K, Asahara M, Suzuki M, Yokota A. Application of the hypervariable region of the $16 \mathrm{~S}$ rDNA sequence as an index for the rapid identification of species in the genus Alicyclobacillus. J Gen Appl Microbiol. 2002;48(5):243-50.

5. Gouws PA, Gie L, Pretorius A, Dhansay N. Isolation and identification of Alicyclobacillus acidocaldarius by 16S rDNA from mango juice and concentrate. Int J Food Sci Technol. 2005;40(7):789-92. 
6. Di Lauro B, Rossi M, Moracci M. Characterization of a $\beta$-glycosidase from the thermoacidophilic bacterium Alicyclobacillus acidocaldarius. Extremophiles. 2006;10(4):301-10.

7. Groenewald WH, Gouws PA, Witthuhn RC. Isolation and identification of species of Alicyclobacillus from orchard soil in the Western Cape, South Africa. Extremophiles. 2008;12(1):159-63.

8. Groenewald WH, Gouws PA, Witthuhn RC. Isolation, identification and typification of Alicyclobacillus acidoterrestris and Alicyclobacillus acidocaldarius strains from orchard soil and the fruit processing environment in South Africa. Food Microbiol. 2009;26(1):71-6.

9. Eckert K, Schneider E. A thermoacidophilic endoglucanase (CelB) from Alicyclobacillus acidocaldarius displays high sequence similarity to arabinofuranosidases belonging to family 51 of glycoside hydrolases. Eur J Biochem. 2003;270(17):3593-602.

10. Chundawat SP, Beckham GT, Himmel ME, Dale BE. Deconstruction of lignocellulosic biomass to fuels and chemicals. Annu Rev Chem Biomol Eng. 2011;2:121-45.

11. Sorek N, Yeats TH, Szemenyei $H$, Youngs $H$, Somerville CR. The implications of lignocellulosic biomass chemical composition for the production of advanced biofuels. Bioscience. 2014:64:192-201.

12. Olcay H, Subrahmanyam AV, Xing R, Lajoie J, Dumesic JA, Huber GW. Production of renewable petroleum refinery diesel and jet fuel feedstocks from hemicellulose sugar streams. Energy Environ Sci. 2013;6(1):205-16.

13. Jae J, Tompsett GA, Lin Y-C, Carlson TR, Shen J, Zhang T, Yang B, Wyman CE, Conner WC, Huber GW. Depolymerization of lignocellulosic biomass to fuel precursors: maximizing carbon efficiency by combining hydrolysis with pyrolysis. Energy Environ Sci. 2010;3(3):358-65.

14. de Souza WR. Microbial degradation of lignocellulosic biomass. In: Silva AK, Da Silva SS, editors. Sustainable degradation of lignocellulosic biomass - techniques, applications and commercialization. InTech; 2013. p. 207-47.

15. Mavromatis K, Sikorski J, Lapidus A, Rio TGD, Copeland A, Tice H, Cheng J-F, Lucas S, Chen F, Nolan M, et al. Complete genome sequence of Alicyclobacillus acidocaldarius type strain (104-IAT). Stand Genomic Sci. 2010;2(1):9-18.

16. La Cara F, Scarffi MR, D'Auria S, Massa R, d'Ambrosio G, Franceschetti G, Rossi M, De Rosa M. Different effects of microwave energy and conventional heat on the activity of a thermophilic B-galactosidase from Bacillus acidocaldarius. Bioelectromagnetics. 1999;20(3):172-6.

17. Gul-Guven R, Guven K, Poli A, Nicolaus B. Purification and some properties of a $\beta$-galactosidase from the thermoacidophilic Alicyclobacillus acidocaldarius subsp. Rittmannii isolated from Antarctica. Enzyme Microb Technol. 2007;40(6):1570-7.

18. Di Lauro B, Strazzulli A, Perugino G, La Cara F, Bedini E, Corsaro MM, Rossi M, Moracci M. Isolation and characterization of a new family 42 $\beta$-galactosidase from the thermoacidophilic bacterium Alicyclobacillus acidocaldarius: identification of the active site residues. Biochim Biophys Acta (BBA) Proteins Proteomics. 2008;1784(2):292-301.

19. Yuan $T$, Yang $P$, Wang $Y$, Meng $K$, Luo H, Zhang W, Wu N, Fan Y, Yao B. Heterologous expression of a gene encoding a thermostable $\beta$-galactosidase from Alicyclobacillus acidocaldarius. Biotechnol Lett. 2008;30(2):343-8.

20. Koivula Y, Hemila H, Pakkanen R, Sibakov M, Palva I. Cloning and sequencing of a gene encoding acidophilic amylase from Bacillus acidocaldarius. J Gen Microbiol. 1993;139(10):2399-407.

21. Schwermann B, Pfau K, Liliensiek B, Schleyer M, Fischer T, Bakker EP. Purification, properties and structural aspects of a thermoacidophilic a-amylase from Alicyclobacillus acidocaldarius ATCC 27009. Eur J Biochem. 1994;226(3):981-91.

22. Matzke J, Schwermann B, Bakker EP. Acidostable and acidophilic proteins: the example of the a-amylase from Alicyclobacillus acidocaldarius. Comp Biochem Physiol Part A Physiol. 1997;118(3):475-9.

23. Morlon-Guyot J, Ordonez RG, Gasparian S, Guyot JP. Pre-harvesting treatments to recover ia a soluble form the cell-bound a-amylase of Alicyclobacillus acidocaldarius grown in liquid culture media containing soluble and granular starch. J Food Sci Technol. 1998;35(2):117-21.

24. Satheesh Kumar G, Chandra M, Mallaiah K, Sreenivasulu P, Choi Y-L. Purification and characterization of highly thermostable a-amylase from thermophilic Alicyclobacillus acidocaldarius. Biotechnol Bioprocess Eng. 2010;15(3):435-40.
25. Morana A, Esposito A, Maurelli L, Ruggiero G, lonata E, Rossi M, Cara FL. A novel thermoacidophilic cellulase from Alicyclobacillus acidocaldarius. Protein Pept Lett. 2008;15:1017-21.

26. Zhang Y, Ju J, Peng H, Gao F, Zhou C, Zeng Y, Xue Y, Li Y, Henrissat B, Gao $\mathrm{GF}$, et al. Biochemical and structural characterization of the intracellular mannanase AaManA of Alicyclobacillus acidocaldarius reveals a novel glycoside hydrolase family belonging to clan GH-A. J Biol Chem. 2008;283(46):31551-8.

27. Ordoñez R, Morlon-Guyot J, Gasparian S, Guyot J. Occurrence of a thermoacidophilic cell-bound exo-pectinase in Alicyclobacillus acidocaldarius. Folia Microbiol. 1998;43(6):657-60.

28. Matzke J, Herrmann A, Schneider E, Bakker EP. Gene cloning, nucleotide sequence and biochemical properties of a cytoplasmic cyclomaltodextrinase (neopullulanase) from Alicyclobacillus acidocaldarius, reclassification of a group of enzymes. FEMS Microbiol Lett. 2000;183(1):55-61.

29. Eckert K, Zielinski F, Leggio LL, Schneider E. Gene cloning, sequencing, and characterization of a family 9 endoglucanase (CelA) with an unusual pattern of activity from the thermoacidophile Alicyclobacillus acidocaldarius ATCC27009. Appl Microbiol Biotechnol. 2002;60(4):428-36.

30. Eckert K, Vigouroux A, Lo Leggio L, Moréra S. Crystal structures of A. acidocaldarius endoglucanase Cel9A in complex with cello-oligosaccharides: strong -1 and -2 subsites mimic cellobiohydrolase activity. J Mol Biol. 2009;394(1):61-70.

31. Pereira JH, Sapra R, Volponi JV, Kozina CL, Simmons B, Adams PD. Structure of endoglucanase Cel9A from the thermoacidophilic Alicyclobacillus acidocaldarius. Acta Crystallogr Sect D Biol Crystallogr. 2009:D65(8):744-50.

32. Thompson DN, Apel WA, Thompson VS, Reed DW, Lacey JA, Henriksen ED. Thermophilic and thermoacidophilic biopolymer-degrading genes and enzymes from alicyclobacillus acidocaldarius and related organisms, methods. Google Patents; 2013.

33. Thompson DN, Thompson VS, Schaller KD, Apel WA, Reed DW, Lacey JA. Thermal and acid tolerant beta xylosidases, arabinofuranosidases, genes encoding, related organisms, and methods. Google Patents; 2013.

34. Deutscher J. The mechanisms of carbon catabolite repression in bacteria. Curr Opin Microbiol. 2008;11(2):87-93.

35. Gorke B, Stulke J. Carbon catabolite repression in bacteria: many ways to make the most out of nutrients. Nat Rev Microbiol. 2008;6(8):613-24.

36. Biely P. Microbial carbohydrate esterases deacetylating plant polysaccharides. Biotechnol Adv. 2012;30(6):1575-88.

37. Deli A, Koutsioulis D, Fadouloglou VE, Spiliotopoulou P, Balomenou S, Arnaouteli S, Tzanodaskalaki M, Mavromatis K, Kokkinidis M, Bouriotis V. LmbE proteins from Bacillus cereus are de- $\mathrm{N}$-acetylases with broad substrate specificity and are highly similar to proteins in Bacillus anthracis. FEBS J. 2010;277(13):2740-53.

38. Viars S, Valentine J, Hernick M. Structure and function of the LmbE-like superfamily. Biomolecules. 2014;4(2):527-45.

39. Mine $S$, Niiyama M, Hashimoto W, Ikegami T, Koma D, Ohmoto T, Fukuda Y, Inoue T, Abe Y, Ueda T, et al. Expression from engineered Escherichia coli chromosome and crystallographic study of archaeal $N, N^{\prime}-$ diacetylchitobiose deacetylase. FEBS J. 2014;281(11):2584-96.

40. Beringer T, Lucht W. Bioenergy and biospheric carbon. In: Lal R, Lorenz K, Hüttl RF, Schneider BU, von Braun J, editors. Recarbonization of the biosphere. Dordrecht: Springer; 2012. p. 481-92.

41. Bhalla A, Bansal N, Kumar S, Bischoff KM, Sani RK. Improved lignocellulose conversion to biofuels with thermophilic bacteria and thermostable enzymes. Bioresour Technol. 2013;128:751-9.

42. Mandalari G, Faulds CB, Sancho Al, Saija A, Bisignano G, LoCurto R, Waldron KW. Fractionation and characterisation of arabinoxylans from brewers'spent grain and wheat bran. J Cereal Sci. 2005;42(2):205-12.

43. Bai Y, Wang J, Zhang Z, Shi P, Luo H, Huang H, Feng Y, Yao B. Extremely acidic $\beta$-1,4-glucanase, CelA4, from thermoacidophilic Alicyclobacillus sp. A4 with high protease resistance and potential as a pig feed additive. J Agric Food Chem. 2010;58(3):1970-5.

44. Nurizzo D, Nagy T, Gillbert HJ, Davies GJ. The structural basis for catalysis and specificity of the Pseudomonas cellulosa a-glucuronidase, GlcA67A. Structure. 2002;10(4):547-56.

45. Zhang Y, Gao F, Xue Y, Zeng Y, Peng H, Qi J, Ma Y. Crystallization and preliminary X-ray study of native and selenomethionyl [beta]-1,4-mannanase AaManA from Alicyclobacillus acidocaldarius Tc-12-31. Acta Crystallogr Sect F Struct Biol Crystall Commun. 2008;64(3):209-12. 
46. Nanavati DM, Thirangoon K, Noll KM. Several archaeal homologs of putative oligopeptide-binding proteins encoded by Thermotoga maritima bind sugars. Appl Environ Microbiol. 2006;72(2):1336-45.

47. VanFossen AL, Verhaart MRA, Kengen SMW, Kelly RM. Carbohydrate utilization patterns for the extremely thermophilic bacterium Caldicellulosiruptor saccharolyticus reveal broad growth substrate preferences. Appl Environ Microbiol. 2009;75(24):7718-24.

48. Bauer MW, Driskill LE, Callen W, Snead MA, Mathur EJ, Kelly RM. An endoglucanase, EgIA, from the hyperthermophilic archaeon Pyrococcus furiosus hydrolyzes $\beta$-1,4 bonds in mixed-linkage $(1 \rightarrow 3),(1 \rightarrow 4)-\beta$-Dglucans and cellulose. J Bacteriol. 1999;181(1):284-90.

49. Liebl W, Ruile P, Bronnenmeier K, Riedel K, Lottspeich F, Greif I. Analysis of a Thermotoga maritima DNA fragment encoding two similar thermostable cellulases, CelA and CelB, and characterization of the recombinant enzymes. Microbiology. 1996;142(9):2533-42.

50. Hall J, Hazlewood GP, Barker PJ, Gilbert HJ. Conserved reiterated domains in Clostridium thermocellum endoglucanases are not essential for catalytic activity. Gene. 1988;69(1):29-38.

51. Shi P, Tian J, Yuan T, Liu X, Huang H, Bai Y, Yang P, Chen X, Wu N, Yao B. Paenibacillus sp. strain E18 bifunctional xylanase-glucanase with a single catalytic domain. Appl Environ Microbiol. 2010;76(11):3620-4.

52. Chang L, Ding M, Bao L, Chen Y, Zhou J, Lu H. Characterization of a bifunctional xylanase/endoglucanase from yak rumen microorganisms. Appl Microbiol Biotechnol. 2011;90(6):1933-42.

53. Rashamuse KJ, Visser DF, Hennessy F, Kemp J, Roux-van der Merwe MP, Badenhorst J, Ronneburg T, Francis-Pope R, Brady D. Characterisation of two bifunctional cellulase-xylanase enzymes isolated from a bovine rumen metagenome library. Curr Microbiol. 2013;66(2):145-51.

54. Breves R, Bronnenmeier K, Wild N, Lottspeich F, Staudenbauer WL, Hofemeister J. Genes encoding two different beta-glucosidases of Thermoanaerobacter brockii are clustered in a common operon. Appl Environ Microbiol. 1997;63(10):3902-10.

55. Han Y, Agarwal V, Dodd D, Kim J, Bae B, Mackie RI, Nair SK, Cann IKO. Biochemical and structural insights into xylan utilization by the thermophilic bacterium Caldanaerobius polysaccharolyticus. J Biol Chem. 2012;287(42):34946-60

56. Mai V, Wiegel J, Lorenz WW. Cloning, sequencing, and characterization of the bifunctional xylosidase-arabinosidase from the anaerobic thermophile Thermoanaerobacter ethanolicus. Gene. 2000;247(1-2):137-43.
57. Bai Y, Huang H, Meng K, Shi P, Yang P, Luo H, Luo C, Feng Y, Zhang W, Yao B. Identification of an acidic a-amylase from Alicyclobacillus sp. A4 and assessment of its application in the starch industry. Food Chem. 2012;131(4):1473-8.

58. Larsbrink J, Izumi A, Ibatullin FM, Nakhai A, Gilbert HJ, Davies GJ, Brumer H. Structural and enzymatic characterization of a glycoside hydrolase family 31 a-xylosidase from Cellvibrio japonicus involved in xyloglucan saccharification. Biochem J. 2011;436(3):567-80.

59. Trincone A, Cobucci-Ponzano B, Di Lauro B, Rossi M, Mitsuishi Y, Moracci M. Enzymatic synthesis and hydrolysis of xylogluco-oligosaccharides using the first archaeal a-xylosidase from Sulfolobus solfataricus. Extremophiles. 2001;5(4):277-82.

60. Bolstad BM, Irizarry RA, Åstrand M, Speed TP. A comparison of normalization methods for high density oligonucleotide array data based on variance and bias. Bioinformatics. 2003;19(2):185-93.

61. Irizarry RA, Hobbs B, Collin F, Beazer-Barclay YD, Antonellis KJ, Scherf U, Speed TP. Exploration, normalization, and summaries of high density oligonucleotide array probe level data. Biostatistics. 2003;4(2):249-64

62. Markowitz VM, Chen IMA, Chu K, Szeto E, Palaniappan K, Grechkin Y, Ratner A, Jacob B, Pati A, Huntemann M, et al. IMG/M: the integrated metagenome data management and comparative analysis system. Nucleic Acids Res. 2012;40(D1):D123-9.

63. Altschul SF, Gish W, Miller W, Myers EW, Lipman DJ. Basic local alignment search tool. J Mol Biol. 1990;215(3):403-10.

64. Gish W, States DJ. Identification of protein coding regions by database similarity search. Nat Genet. 1993;3(3):266-72.

65. Tamura K, Stecher G, Peterson D, Filipski A, Kumar S. MEGA6: molecular evolutionary genetics analysis version 6.0. Mol Biol Evol. 2013;30(12):2725-9.

66. Edgar RC. MUSCLE: multiple sequence alignment with high accuracy and high throughput. Nucleic Acids Res. 2004;32(5):1792-7.

67. Edgar RC. MUSCLE: a multiple sequence alignment method with reduced time and space complexity. BMC Bioinform. 2004;5(1):113.
Ready to submit your research? Choose BMC and benefit from:

- fast, convenient online submission

- thorough peer review by experienced researchers in your field

- rapid publication on acceptance

- support for research data, including large and complex data types

- gold Open Access which fosters wider collaboration and increased citations

- maximum visibility for your research: over $100 \mathrm{M}$ website views per year

At BMC, research is always in progress.

Learn more biomedcentral.com/submissions 